\title{
LA NATURALEZA POLÍTICA DE LA UNIÓN PERSONAL Y DE LA UNIÓN REAL COMO FORMAS MONÁRQUICAS DURANTE LA MODERNIDAD
}

\section{THE POLITICAL NATURE OF THE PERSONAL UNION AND THE REAL UNION AS MONARCHICAL FORMS DURING MODERNITY}

\author{
Sergio Raúl Castaño \\ CONICET-Universidad Nacional del Comahue-UNSTA
}

\begin{abstract}
SUMARIO. I. REPLANTEAMIENTO DEL MARCO INSTITUCIONAL GENERAL POR LA HISTORIOGRAFÍA CONTEMPORÁNEA. 1.1. La introducción del tema de las monarquías múltiples por Königsberger. 1.2. La fijación de la figura como tópos historiográfico por John Elliot; y algunas precisiones terminológicas. II. LAS UNIONES DE ESTADO MONÁRQUICAS Y SU TRATAMIENTO POR EL DERECHO POLÍTICO. 2.1. Breve caracterización de sus formas principales: Unión personal y Unión real. 2.2. Sobre la raigambre de la Unión personal y de la Unión real como Uniones de reinos (y sobre su respectiva juridicidad). 2.3. Sintesis y conclusiones parciales. 2.3.1. El problema de un género común. 2.3.2. La Unión personal como forma tradicional típica. 2.3.3. La Unión real como proceso de descentralización. III. DOS EJEMPLOS HISTÓRICOS CLÁSICOS DE UNIÓN PERSONAL Y DE UNIÓN REAL. CONTEXTO HISTÓRICO Y DISEÑO INSTITUCIONAL FUNDAMENTAL. 3.1. Inglaterra y Escocia. 3.2. Austria y Hungria. IV. ALGUNOS MODOS SUI GENERIS O IMPROPIOS DE LA UNIÓN PERSONAL: CONFORMACIÓN A PARTIR DE LA CONQUISTA, DOMINIO O PATRIMONIO DEL MONARCA; LA COMMONWEALTH. 4.1. El Ducado de Lancaster y la corona inglesa. 4.2. El Ducado de Lauenburg y Prusia. 4.3. El Estado independiente del Congo y Bélgica. 4.4. El caso del Imperio Británico y la Commonwealth bajo el Estatuto de Westminster. V. SÍNTESIS CONCLUSIVA.
\end{abstract}

\section{Resumen:}

El presente estudio aborda el tema de las Uniones monárquicas. So objeto es dilucidar la naturaleza del tipo de la Unión personal y del de la Unión real, así como echar una vista de conjunto sobre los casos más representativos de vinculaciones monárquicas sui generis operadas en los ss. XIX y XX.

\begin{abstract}
:
The present study deals with the issue of monarchical Unions. Its purpose is to elucidate the nature of the type of the personal Union and that of the real Union, as well as to give an account of the most representative cases of sui generis monarchical unions operated in the $19^{\text {th }}$. and $20^{\text {th }}$. centuries.
\end{abstract}

Palabras clave: Unión personal, Unión real, Monarquía.

Key Words: Personal Union, Real Union, Monarchy, First/Early Modernity. 


\section{REPLANTEAMIENTO DEL MARCO INSTITUCIONAL GENERAL POR LA HISTORIOGRAFÍA CONTEMPORÁNEA 1}

\subsection{La introducción del tema de las monarquias múltiples por Königsberger}

Ya se halla canónicamente reconocido, en la cuestión que nos ocupará en las siguientes páginas, que el escrito inaugural de su contemporáneo tratamiento historiográfico es la Lecture pronunciada por el Prof. Königsberger en el King's College de la Universidad de Londres en $1975 .^{2}$ El tema general de esa lección académica fue el de los avatares de la puja entre el trono y el parlamento a lo largo de la primera modernidad.

Dicho tema -que, en pocas palabras, cabría resumir como el proceso político divergente que desembocará ya en el afianzamiento de la monarquía (absolutismo), ${ }^{3}$ ya en la conformación de monarquías de tipo parlamentario- es abordado por Königsberger desde la perspectiva de la distribución del poder. A partir de la lucha histórica de esas dos instituciones, trono y representación ante el trono, nuestro autor detecta tres situaciones politicas distintas de ella resultantes, grupos típicos que subsumirian a la casi totalidad de los escenarios institucionales de los reinos europeos entre los ss. XV y XVIII (con la saliente excepción, aclara, del Sacro Imperio -donde la contraparte del Emperador son, derechamente, Estados-; y de Suecia, en donde el predominio de una y otra parte conoció oscilaciones inusuales). ${ }^{4}$ Ahora bien, Königsberger busca alguna explicación general que dé cuenta, acudiendo a factores comunes, de los variados procesos que configuraron esas situaciones políticas diversas. Para ello apela a dos interpretaciones históricas célebres, la del gran historiador del Derecho Otto von Hintze y la del sociólogo Norbert Elias. Aunque con la brevedad que impone a estas menciones el desarrollo de nuestro tema central, recalaremos con mayor detalle en las consideraciones de Hintze, dada su riqueza para la historia politica.

En efecto, en su clásico estudio "Typologie der ständischen Verfassungen", ${ }^{5}$ Hintze delinea dos grandes grupos de constitución (monárquico)-estamental,

\footnotetext{
1 Agradezco especialmente al Prof F. Martínez Martínez por haberme facilitado la copia de los libros de Kunz y Brunialti

2 Königsberger Helmut Georg, "Monarchies and Parliaments in early Modern Europe. Dominium Regale or Dominium Politicum et Regale”, Theory and Society, $\mathrm{n}^{\circ}$ 5, 1978, pp. 191-217. Como artículo sería presentado con ligeras variantes en un simposio celebrado en el Castillo de Reisemberg en abril de ese mismo año, y aparecería luego en P. Gleichmann - J. Goudsblom - H. Korte (eds.), "Human Figurations. Essays for Norbert Elias", Amsterdam, 1977.

3 Corresponde hacer la salvedad de que el término “absolutismo" ("des-ligamiento", libertad: "el acusado ha sido absuelto") significa politicamente, respecto del poder, ya la capacidad de erigirse en instancia inconsulta de decisión, con prescindencia de la anuencia o colaboración de las otras instancias sociales; ya la no sujeción del poder a otra norma fuera de las que emanan del propio poder, es decir, la preterición de toda necesidad deóntica de obligación frente al derecho consuetudinario, la ley natural y la ley divina. Es pertinente señalar que en la temprana modernidad la deriva absolutista manifestó el primer sentido del término, mas no formal ni principalmente el segundo (fenómeno que recién comenzará a verificarse con acuidad a partir de Rousseau -y Hegel-).

4 Königsberger Helmut Georg, "Monarchies and Parliaments in early Modern Europe. Dominium Regale or Dominium Politicum et Regale”, op. cit., pp. 193-195.

5 Cfr. Hintze Otto, Staat und Verfassung, Gerhard Oestreich (ed.), Vandenhoek \& Ruprecht, Göttingen, 1970, pp. 120-139.
} 
entendiendo por este último término aquellas asociaciones politicas en las que los meliores et majores terrae, organizados corporativamente, representan ante el príncipe (ante el poder, en última instancia) al reino o al señorío como un todo. ${ }^{6}$ Hintze distingue, dentro del conjunto de los reinos europeos de la temprana modernidad, dos tipos ideales que, como tales, no se han realizado acabadamente en ninguna parte, pero que no obstante señalan algunos rasgos definitorios de la estructura de poder y del devenir institucional, según que en uno u otro grupo haya terminado imponiéndose el factor real o el factor estamental-comunitario. En el primer caso nos las habemos con el "sistema de dos cámaras (Zweikammersystem)", en el segundo con el "sistema de tres cortes (Dreikuriensystem)". Aquél se verificó, indica Hintze, paradigmáticamente en Inglaterra; mientras que el segundo en Francia. Castilla se acercó al primer tipo; los principados alemanes al segundo; pero el Imperio tuvo más bien semejanzas con el primero (rasgo que condijo con su naturaleza pluriestatal). En el sistema inglés de dos cámaras se hallaban, por un lado, los grandes del reino (laicos y eclesiásticos); y, por otro, los representantes del país y del pueblo, cámara en la que se nucleaban -juntos- nobles y burgueses. ${ }^{7}$ En el sistema de tres cortes -al que Hintze denomina "nuevo" como opuesto al "antiguo", sin duda por su virtualidad absolutista- los grandes del reino ven reducirse su influencia y en Francia, concretamente, los Parlamentos terminan convirtiéndose en cortes de justicia. ${ }^{8}$

A la hora de rastrear las principales causas que podrian explicar la conformación de ambos tipos y, a la postre, marcar el triunfo del nuevo sobre al antiguo, Hintze recala en dos factores. ${ }^{9}$ El primero consiste en un elemento geográfico-histórico-político: es el hecho de la pertenencia -o no- al ámbito del antiguo Imperio carolingio. ${ }^{10} \mathrm{Es}$ en este ámbito, precisamente, donde tras la desaparición del Imperio se impuso un orden político feudal. Ahora bien, Brie juzga al orden feudal como disolvente (auflösend) de la antigua asociación de señores y vasallos, así como elemento coadyuvante para que el poder real terminara fortaleciéndose con prescindencia de los grandes del reino. ${ }^{11}$ Junto con el papel socialmente revulsivo del orden feudal, Hintze señala que fue también en el ámbito carolingio donde la tradición romanista prohijó una clase de mentalidad burocrática, racionalista y centralista que contribuyó a cimentar el predominio del soberano.

6 "Typologie der ständischen Verfassungen" Hintze Otto, Staat und Verfassung, op. cit., p. 121.

7 "Tal mezcla de estamentos no se halla habitualmente en ninguna parte; es lo característico de Inglaterra" (Hintze Otto, Staat und Verfassung, op. cit., p. 128). Así, en Castilla la baja nobleza no se hallaba representada en las Cortes, como sí lo estaban las ciudades -un fenómeno similar a lo ocurrido en el Imperio.

8 Hintze Otto, Staat und Verfassung, op. cit., pp. 126-134.

9 Hintze Otto, Staat und Verfassung, op. cit., pp. 135-137.

10 Con la excepción de las Dos Sicilias (gobernadas, sin embargo, por dinastías francesas y aragonesas), observa Hintze, el sistema de tres cortes tuvo arraigo sobre todo en el solar carolingio.

11 Hintze señala al respecto que en Inglaterra, al contrario de en Francia, los señoríos territoriales no tenían carácter hereditario -cabría aquí agregar por nuestra parte que lo propio, justamente, ocurria en Castilla-; esto contribuyó a prevenir que adquirieran carácter patrimonial en manos de los nobles y, con ello, conservó y salvó del desmembramiento a la asociación estatal, sostiene Hintze (Hintze Otto, Staat und Verfassung, op. cit., pp. 135-136). 
Königsberger reconoce el valor del planteo de Hintze, pero le objeta el caso de los Países Bajos, región carolingia que conoció varias formas de sistemas de representación y que finalmente produjo, en las dos unidades políticas que resultaron de ella, dos resultados antitéticos: en las Provincias Unidas la abolición de la monarquía por los estamentos; en el Flandes hispánico el crepúsculo de éstos ante el poder real. ${ }^{12}$

Por su parte Elias, en su estudio "La génesis social del Estado"13 utiliza la figura de mecanismos para explicar la consolidación del poder del soberano en la edad moderna. El primero de tales mecanismos es el del monopolio de la dominación, a la vez financiero y militar. ${ }^{14}$ Este proceso político, análogo al de los agentes económicos, se funda en la acumulación de dominio sobre la tierra y desemboca en el monopolio de la fuerza física. ${ }^{15}$ Por otro lado opera decisivamente el mecanismo real. Éste actúa en una sociedad crecientemente diferenciada, en la que los intereses son diversos y donde los grupos nunca llegan a coaligarse para disputar al soberano el poder político. Es en este escenario de "equilibrio multipolar" donde el rey se erige como árbitro último entre esos estamentos que, además de no formar un frente político común, se recelan y compiten entre sí. Como remate, debido a la necesidad de atender un aparato administrativo cada vez más abarcador y complejo, aparece un postrer mecanismo, el del funcionariado, que será órgano indispensable de la cristalización del poder central. Finalmente, el derrotero del predominio del poder monárquico culminará al alcanzar éste el monopolio fiscal.

Con todo y proclamar el valor de la "poderosa teoría de las fuerzas dinámicas de la historia europea" propuesta por Elias, Königsberger no deja de señalar sus limitaciones, debidas (en prieta sintesis) a la generalidad sociológica de que adolece, y que impide determinar los perfiles concretos de los reinos que dominaron Europa y los procesos particulares que llevaron a la configuración de tal mapa político. ${ }^{16}$

Es aquí donde Königsberger introduce la categoría que nos ocupa. Rara vez la disputa entre monarca y parlamento tuvo lugar en sistemas políticos cerrados, observa. Pues entre finales de la edad media y el comienzo de la modernidad, por

12 Königsberger Helmut Georg, "Monarchies and Parliaments in early Modern Europe. Dominium Regale or Dominium Politicum et Regale”, op. cit., p. 198. Es evidente que la objeción queda relativizada por el hecho de que en una de las partes de Flandes triunfó la insurrección y se logró la independencia de la corona española, mientras que la otra parte permaneció unida a ésta "aeque principaliter". El propio Königsberger indicará más adelante que, en efecto, la injerencia exterior constituye un factor relevante a la hora de definir constitucionalmente a una comunidad.

13 Incluido en "Las transformaciones de la sociedad", cap. III, a su vez, de El proceso de la civilización, s/d trad., Buenos Aires, FCE, 1993; "La génesis ..." se halla en pp. 333 y ss. Elias Norbert, El proceso de la civilización, Fondo de Cultura Económica, Buenos Aires, 1993, pp. 333 y ss.

14 Cfr., para lo que sigue, Elias Norbert, El proceso de la civilización, op. cit., pp. 345 y ss.

15 Elias observa, por lo demás, que la actividad económica como la conocemos modernamente (i. e., la economía capitalista) sólo ha podido tener lugar tras la instauración de dicho monopolio político de la fuerza, que permitió la libre circulación y la seguridad de los agentes económicos en un amplio territorio.

16 Königsberger Helmut Georg, "Monarchies and Parliaments in early Modern Europe. Dominium Regale or Dominium Politicum et Regale”, op. cit., pp. 199-202. 
cuatro o cinco siglos, la mayor parte de las monarquías eran "compuestas" (composite monarchies). Las hubo compuestas por reinos separados, incluso por el océano, como la monarquía hispánica o Inglaterra y Hannover; y contiguas, como Polonia y Lituania. La puja por el poder, en este escenario, debía tener en cuenta a una corona común lidiando con parlamentos de distintos reinos o señorios. En principio, eso hubiera hecho pensar en una ventaja para el monarca, enfrentado con fuerzas dispersas. Sin embargo, un haz de circunstancias particulares hizo que si -por poner el ejemplo de la monarquía compuesta par excellence, la de los Austria hispánicos- el rey en algunos reinos consiguió imponerse sobre las fuerzas locales (caso de Carlos V y los comuneros), en otros los parlamentos de los reinos mantuvieron con éxito su funcionamiento y prerrogativas (caso de Sicilia). ${ }^{17}$

Sea como fuere de lo últimamente dicho, lo que a estas líneas interesa es que el tema de las monarquías compuestas había sido replanteado y reactualizado por la historiografia contemporánea.

\subsection{La fijación de la figura como tópos historiográfico por John Elliot; y algunas precisiones terminológicas}

El historiador británico Elliot, renombrado especialista en la temprana modernidad y autoridad en historia hispánica, recoge en un artículo publicado en 1992 la fértil observación de Königsberger. ${ }^{18}$ Elliot abre su trabajo con una confirmación impactante: una Europa que hacia 1500 incluía alrededor de 500 unidades política más o menos independientes se transformó en una que hacia 1900 sólo reconocía 25 de tales entidades. ${ }^{19}$ El Estado-nación, con su fuerza centripeta, unido al principio de nacionalidades, ganará vigencia frente a la "anomalia"20 tradicional del Imperio de los Habsburgo, que aún pervivía entrado el s. XX. Elliot recoge la apreciación de que la mayor parte de los Estados de la temprana modernidad eran Estados compuestos (incluyendo el caso de varios bajo soberanía de un mismo príncipe), sea que se tratara de reinos contiguos, sea que se tratara de reinos separados por el mar. El historiador británico se ocupa enseguida del ilustre ejemplo doctrinal de Solórzano Pereira, quien echó el ruedo las categorias (venidas del derecho y la canonística) de uniones accesorie y aeque principaliter. ${ }^{21}$

17 Cfr. Königsberger Helmut Georg, "Monarchies and Parliaments in early Modern Europe. Dominium Regale or Dominium Politicum et Regale”, op. cit., pp. 202-205 y 213.

18 Se trata de Elliot John, "A Europe of composite Monarchies", Past and Present, $\mathrm{n}^{\circ}$ 137-1, 1992, pp. 48-71.

19 Por su parte Mark Greengrass se explaya sobre la variopinta situación de la composición politica de la Europa de los '500 y acota un dato sin duda significativo. Antes de Napoleón, 294 entidades politicas pertenecientes al ámbito del Sacro Imperio se tenían por independientes; hacia 1820, ya habiendo desaparecido éste, tales unidades politicas no pasaban de 20 (cfr. Greengrass Mark, Conquest and Coalescence, Edward Arnold, Londres, 1991, pp. 2-3).

20 Elliot John, “A Europe of composite Monarchies”, op. cit., p. 49, subrayado de Elliot.

21 Sobre este tema en Solórzano cfr. Castaño Sergio Raúl, "El problema de las Indias en la corona de Castilla. Una exégesis de la Política Indiana, de Juan de Solórzano", Revista de Historia del Derecho, $n^{\circ} 56,2018$, pp. 1-39. 
Elliot repasa las notas más salientes de estas formaciones políticas, así como señala sus puntos débiles, tales la inevitable ausencia del monarca en alguna de sus capitales y la eventual asimetría de poder entre las partes. Sin embargo, no deja de apuntar elementos de contrapeso a tales deficiencias, en particular la creación de vínculos de lealtad al monarca que trascendian el ámbito de los reinos particulares; o la uniformidad religiosa. ${ }^{22}$ Elliot establece asimismo sugerentes paralelismos históricos entre las uniones más representativas de la temprana modernidad, ante todo las de los Habsburgo, los Estuardo/Hannover y los Borbones. Contrariando las tendencias crecientemente centralistas de los reyes -observa-, sólo un "sistema de patronazgo" podía respetar la naturaleza de la monarquía compuesta (identificada por nuestro historiador con el modo aeque principaliter), basada en una unión dinástica laxa, y evitar que ella desapareciese -sea por la integración del reino menor, sea por la disolución del vínculo político entre ambos reinos- ${ }^{23}$ En ese contexto, la solución de los Habsburgo resultó ser la que mejor preservó el estilo de la unión aeque principaliter (figura común a la Unión personal y a la Unión real), mientras en el resto de Europa se sentaban las bases del Estado unitario contemporáneo, con el paradigma precursor de la monarquía borbónica. Finalmente, es dable remarcar con Elliot cómo la forma política propia de la unión aeque principaliter resultó a la vez condicente y manifestativa del espíritu del mundo tradicional según pervivía todavía en la temprana modernidad, "con su profundo respeto por las estructuras corporativas y por los derechos consuetudinarios, privilegios y costumbres". ${ }^{24}$

Esa última observación acerca del carácter descentralizado, plural y participativo (en el plano estamental) de las monarquias tradicionales torna pertinente mencionar la distinción de otro destacado historiador inglés, Conrad Russel, entre monarquias compuestas y reinos múltiples. En efecto, este autor considera que a pesar de la aparente sinonimia de ambas locuciones, monarquías como la francesa podían considerarse compuestas, dada la ausencia de una uniformidad soberana y normativa a la manera postrevolucionaria (el reino de

22 Elliot John, “A Europe of composite Monarchies”, op. cit., pp. 55-61.

23 Elliot John, “A Europe of composite Monarchies”, op. cit., p. 49, pp. 64-68.

24 Elliot John, “A Europe of composite Monarchies”, op. cit., pp. 68-69. Y ése fue precisamente el modo en que se expandió la monarquía hispánica bajo los Austria: salvo Navarra y las Indias, le decía el Conde-Duque de Olivares a Felipe IV, "todos vuestros dominios han sido adquiridos por derechos dinásticos", recuerda el mismo Elliot en "The Spanish Monarchy and the Kingdom of Portugal: 1580-1640”, en Conquest and Coalescence, op. cit., p. 50. Con todo, vale remarcar que Navarra conservó su régimen jurídico y se unió bajo forma de Unión personal; y que las Indias tuvieron un ordenamiento jurídico y un órgano de dirección supremo propios. Tal fue el estilo de los Habsburgo hispánicos: acumulación, no integración (Elliot, p. 63). No en vano el lema de los Habsburgo era Bella gerant alii. Tu, felix Austria, nube. Y el aura de este espíritu, como identificado con los reinos de España, sobrevivió en la dinastía Habsburgo cuando ella ya no reinaba allí -y por el contrario la Nueva Planta borbónica ya había arrasado con el perfil compuesto de la monarquía hispánica-. Fue sin duda por esa razón por la que el Emperador 1lamó "Consejo Supremo de España" al organismo que gobernaría las antiguas posesiones italianas de España que habían pasado a jurisdicción de Austria: "La veintena de años durante la que el mencionado Consejo se denominó 'de España' es un testimonio elocuente de la perdurable visión europea de la Monarquía española como Monarquía compuesta”, acota Gil Pujol Xavier en "Visión europea de la Monarquía española como Monarquía compuesta”, en C. Russell y J. Andrés-Gallego (eds.), Las monarquías del Antiguo Régimen, ¿monarquias compuestas?, Complutense, Madrid, 1996, p. 94. 
Francia era un "patchwork de jurisdicciones"). ${ }^{25}$ Sin embargo, no era un reino múltiple, sino una única monarquia. Contrariamente, Inglaterra, sostiene Russell, sin perjuicio del pluralismo jurídico tradicional, ya era una monarquía unida ("unitaria", desde el punto de vista del ejercicio del poder, la llama Russell). ${ }^{26}$ Y esa monarquía, así consolidada en su unidad, constituyó un reino múltiple con Escocia. Lo característico de la temprana modernidad, remata nuestro autor, es "la ausencia de ambas cosas juntas": es decir que en esos siglos no faltaba por lo menos una de esas formas politicas. ${ }^{27}$

Para Ronald Asch, por su lado, lo que Otto Brunner llamó "monarchische Staatenverbindung (unión monárquica de Estados)", aplicada a la monarquía de Viena hasta su fin en 1918 (una "monarchische Union ihrer Königreiche und Länder, die jede für sich Ständestaaten waren" -Brunner, Land und Herrschaft, 1965, p. 447) sería asimilable a la "composite monarchy" anglosajona. Pero no asi a la zusammengesetzte Staatlichekeit (estatalidad compuesta), como correspondió al Imperio, constituido por una liga de príncipes y ciudades con una corona en su cima. $^{28}$

\section{LAS UNIONES DE ESTADO MONÁRQUICAS Y SU TRATAMIENTO POR EL DERECHO POLÍTICO}

\subsection{Breve caracterización de sus formas principales: Unión personal y Unión real}

El tema que nos ocupa en este estudio recibió sostenida atención de la doctrina jurídico-política en la época en que estas formas monárquicas todavía formaban parte de la realidad institucional vigente. De allí el especial interés teórico que reviste la compulsa de las obras de los grandes teóricos del Estado, constitucionalistas e internacionalistas de finales del s. XIX y comienzos del XX.

Las Uniones de Estados, ha dicho uno de los grandes especialistas alemanes en el tema, tienen una primera clasificación en la yuxtaposición o supra y

25 Todavía bajo Luis XV, una declaración del Parlamento de Aix sobre la unión del condado de Provenza con el reino de Francia expresaba: “... non comme membre accessoire de l'état, mais comme état égal et nullement subordonné, unie non a l'État, mais a la Couronne, non pour suivre les maximes d'une autre nation, mais pour voir affermir les siennes sous l'autorité d'un souverain plus puissants, libre envers la France de toute dépendance" (citado por Asch Ronald, "Die Stuart Monarchie als 'composite monarchy': Supranationale Staatsbildung in Grossbritanien und Ireland im 17. und frühen 18 Jahrhundert", en Der Staat, Beiheft 16: Zusammengesetzte Staatlichkeit in der europäischen Verfassungsgeschichte, Duncker \& Humblot, Berlin, 2006, pp. 144-145).

26 Idéntico juicio sobre la contextura politica inglesa en Asch Ronald, "Die Stuart Monarchie als 'composite monarchy': Supranationale Staatsbildung in Grossbritanien und Ireland im 17. und frühen 18 Jahrhundert", op. cit., pp. 141 y 144.

27 Russell Conrad, "Gran Bretaña a comienzos del s. XVII: monarquía compuesta y reino múltiple”, en Conrad Russell y J. Andrés-Gallego (eds.), Las monarquias del Antiguo Régimen, ¿monarquias compuestas?, op. cit., pp. 31-36. Russell entiende "reino múltiple" como el modo típico de la unión aeque principaliter, al decir de la tradición de Solórzano; o "lo que los ingleses llamaron una unión imperfecta”, según Russell: o sea, las Uniones personales (p. 36).

28 Cfr. Asch Ronald, “Die Stuart Monarchie als 'composite monarchy': Supranationale Staatsbildung in Grossbritanien und Ireland im 17. und frühen 18 Jahrhundert", op. cit., pp. 142 y 143. 
subordinación de sus miembros (i.e., las organizaciones políticas). ${ }^{29} \mathrm{El}$ espectro de realidades jurídicas al que apunta aquí Sigfried Brie es muy amplio, y comprende todo el abanico de posibilidades que cabe dentro de las vinculaciones juridicas entre Estados, desde uniones transitorias y acotadas, como una alianza militar, hasta las formaciones cuasi-politicas y politicas, como la confederación (Staatenbund) y el Estado federal (Bundestaat). En tal plexo se hallan también las Uniones monárquicas de Estados (scl., reinos). Canónicamente, estas uniones son dos: la Unión personal y la real, "conceptos típicos que [subsumen] ciertas formas empíricas", al decir de García-Pelayo. ${ }^{30}$

La Unión personal (el nombre de la locución fue introducido por Pütter a fines del s. XVIII) ${ }^{31}$ sostiene nuestro autor, consiste en un ejemplo de unión casual, en la que funciones de diversos poderes politicos coordinados confluyen en la misma persona física. ${ }^{32}$ Se trata en general de reuniones (Zusammentreffen) similares aunque distintas de aquellas ligas de Estados con una organización y un fin comunes. Esa comunidad casual (zufällige Gemeinsamkeit) del soberano de una pluralidad de Estados no posee un fundamento jurídico -y allí estriba para Brie el criterio para distinguirla de otras organizaciones con las que sólo guardan una similitud exterior-: la comunidad casual del órgano supremo no acarrea efectos jurídicos para los poderes de los Estados involucrados, y por tanto no representa ni el efecto ni la causa de una unión jurídica de Estados, señala Brie. En otros términos, la designación de la misma persona física como monarca de dos reinos, bajo la forma de una investidura que no obedece a una decisión reciproca previa y consciente de las respectivas conducciones de los reinos involucrados -pero, sobre todo, la carencia de efectos jurídicos en el ejercicio del

\footnotetext{
29 Brie Sigfried, Theorie der Staatenverbindungen, Stuttgart, Ferdinad Enke, 1886, p. 24.

30 García Pelayo Manuel, Derecho constitucional comparado, Madrid, Alianza, 1993, p. 205.

31 Pütter Johann Stephan, Beyträge zum teutschen Staats- und Fürsten-Rechte (1777) -citado por Schmoeckel Mathias, "Personal Union of States: "A General Term of International Law or a Concept for a German Schleswig-Holstein?”, p. 5, SSRN:
} http://dx.doi.org/10.2139/ssrn.3020696 [consultado el 12 de octubre de 2019]. Para la historia del término y de la doctrina temprana sobre la Unión personal cfr. las pp. 1-13 de ese artículo.

32 Dejamos aquí de lado la subdivisión que hace Brauneder entre unas Uniones personales en su "forma clásica", que consistiría en la unión de varios países bajo un príncipe común; y una "así llamada unión dinástica" (que a su vez podría ser "dividida" o "indivisa"), en la cual una pluralidad de personas unía varios territorios, que quedaban bajo un mismo señorio (dinásticohereditario) a partir de distintas investiduras (cfr. Brauneder Wilhelm, "Die Habsburgermonarchie als zusammengesetzter Staat", en Der Staat, Beiheft 16: Zusammengesetzte Staatlichkeit in der europäischen Verfassungsgeschichte, pp. 224-225). Consideramos que esta última forma, en la que el patrimonio de la corona se acrecienta mediante sucesivas adquisiciones hereditarias, constituye el modo propio (si no clásico, sí por lo menos típico) en que la Unión personal se manifestó históricamente, signado esencialmente por su carácter dinástico-incluyente. Si bien en la Unión personal el entrecruzamiento de lineas sucesorias se produce en una persona física individual; a su vez esa misma persona transmitirá su título a sus legítimos sucesores, de acuerdo con la ley dinástica vigente en cada reino. Todo ello, por supuesto, sin desconocer que se operaban formas de Unión personal en las que la vinculación entre las coronas dependía respecto de una de ellas- de una investidura particular no hereditaria, razón por la cual tales Uniones se extinguían al dejar el trono el así investido. Era el caso de la corona electiva del Sacro Imperio Romano Germánico. Otro ejemplo lo ofrece la Unión personal entre Castilla y Aragón y el Imperio, disuelta tas la abdicación de Carlos de Habsburgo. 
poder en cada reino-, excluye a la Unión personal del tipo de las Uniones de Estados. ${ }^{33}$

En la Unión real, forma pacticia de vinculación entre dos reinos, ${ }^{34}$ el ejercicio de la potestad soberana se ve afectado por las instituciones comunes introducidas a partir del tratado de unión. Brie define a la Unión real como una asociación de Estados con comunidad jurídica de la persona del soberano (monárquico). En ese lugar juzgará que esta forma, precisamente, sólo le compete a entidades políticas de naturaleza monárquica. En efecto, aduce Brie, si el órgano supremo fuera un colegio o dieta, ésta debería decidir por mayoria, en cuyo caso quedaría instituida una voluntad común por sobre los Estados partes, lo cual contradiría la esencia pacticia de la Unión real; y si se tratara de un presidente, el mecanismo de elección periódica y la responsabilidad de éste antes las cámaras respectivas tampoco parecería condecir con la naturaleza de la Unión real. Así pues, su definición debe quedar limitada a los regímenes monárquicos. ${ }^{35}$

Por su parte, en su clásica obra de referencia en este tema, Georg Jellinek también separa, más que distingue, la Unión personal de la Unión real. ${ }^{36}$ A su juicio el tratamiento que suele recibir la primera adolece del defecto de trasladar esquemas propios del Estado moderno a realidades signadas por el derecho político tradicional. Las uniones de Estados pueden ser de cuatro clases, indica Jellinek: o bien distintas partes se reúnen en una unión política plena (vollkommenen Union); o bien un Estado se halla conformado por miembros que también son estados, aunque no soberanos, tal por ejemplo el Estado federal; o bien se trata de una comunidad basada en la voluntad coincidente de sus partes, tal como en el caso de la Unión real; o bien, por fin, la Unión personal, en la que la comunidad física de monarca se produce por circunstancias distintas a las de un acuerdo recíproco. En este caso nos hallamos ante lo que materialmente ofrece el aspecto de una unión de Estados. Ahora bien, tanto la forma propia de la monarquía absoluta -que garantiza al príncipe un radio de actividad personal ilimitado, el cual licuaría los límites de la Unión-; cuanto aquélla propia del Estado constitucional ${ }^{37}$-en la que los asuntos comunes exigirian un acuerdo jurídico explícito de los reinos unidos, lo cual excedería de la mera coincidencia fisica del monarca-; ambas se muestran inadecuadas para dar cuenta de la naturaleza de la Unión personal.

La Unión personal, define Jellinek, consiste en "una comunidad jurídicamente casual de varios Estados a través de la persona del soberano,

33 Brie Sigfried, Theorie der Staatenverbindungen, op. cit., pp. 60-61. En el mismo sentido cfr. Kunz Josef, Die Staatenverbindungen, Kohlhammer, Stuttgart, 1929, p. 248.

34 Aunque Brie ofrece el raro ejemplo de una Unión real compuesta por más de dos reinos: la unión de Kalmar (1397), integrada por los tres reinos nórdicos bajo el mismo soberano (Brie Sigfried, Theorie der Staatenverbindungen, op. cit., p. 79).

35 Brie Sigfried, Theorie der Staatenverbindungen, op. cit., pp. 69-70. Así también Kunz Josef, Die Staatenverbindungen, op. cit. p. 419.

36 Para lo que sigue: Jellinek Georg, Die Lehre von den Staatenverbindungen, Goldbach, Keip Verlag, 1996 (reimpr. fotomecánica de la 1a. ed. 1882), pp. 82-88.

37 Traducimos "staatsrechtlich" por "constitucional" atendiendo al sentido que el autor da aquí al término, como contradistinto de "völkerrechtlich" (“jurídico-internacional”). 
quien posee jurídicamente tantas personalidades cuantos Estados rige". 38 Para Jellinek, por un lado, el carácter necesariamente monárquico de la Unión no ofrece dudas -al punto de que no aduce argumentos para sostenerlo-. Por otro, se trata de una Unión histórica, no jurídica, de reinos. ${ }^{39} \mathrm{Su}$ significación política, observa el maestro de Heidelberg, estriba en que el gran peso de la figura de un monarca permite que los diversos Estados unidos a su persona cumplan objetivos contrapuestos en el ámbito internacional; de allí el recelo de las posiciones políticas modernas de "equilibrio de poderes" a la constitución de Uniones personales entre las grandes potencias (caso de la paz de Utrecht y Viena -1725-, vetando tal unión entre los reinos de Francia y España, regidos por borbones).

En torno de la politicidad ut sic de esta forma politica cabe hacer una observación en el plano sistemático esencial del derecho político. La alternativa de que uno de los reinos se halle en guerra mientras el otro permanezca neutral ante el enemigo del primero resulta para Jellinek posible. Mas no sería nunca factible (fuera de elucubraciones -in malam partem teóricas- de algunos profesores) que los reinos unidos emprendieran hostilidades uno contra otro, de suerte que la misma persona física del soberano se hallase desdoblada en dos personas jurídicas en guerra entre sí. Esta imposibilidad en el plano de la realidad efectiva pone sobre la pista de un rasgo propio de las uniones monárquicas en general -i.e., también de las Uniones reales-. ${ }^{40}$ En estas formaciones politicas sui generis, sus partes, los reinos, adolecen de lo que cabría llamar un déficit en su plena politicidad. Sopesando el problema en el contexto de los planteos de Carl Schmitt sobre la federación y el derecho a la guerra, ${ }^{41}$ cabría señalar que la imposibilidad en que se hallan los reinos coaligados de tomarse reciprocamente como enemigos indicaría su pertenencia a una unidad superior. Ahora bien, tal unidad no estaria fundada en la homogeneidad de los pueblos sino en la comunidad del monarca; sería ésta la que daría razón de la exclusión de la enemistad entre los dos reinos y de la consiguiente renuncia permanente al ius belli por parte de ambos. En este sentido cabria suponer un modo de menoscabo en la plena politicidad e independencia de los reinos involucrados, por cuanto éstos se tomarian reciprocamente como partes homogéneas sin serlo en realidad. Podría objetarse que esta perspectiva schmittiana adolece a su vez de un cierto estatalismo; como sea, la imposibilidad de la guerra recíproca ya podría constituir el signo de una incoada o incipiente -siquiera mínima-integración, que impediría referirse a los reinos como plenamente independientes.

La "convergencia jurídicamente casual" que funda a la Unión personal, además de por entrecruzamiento de líneas sucesorias, también puede producirse por elección. Ése es, en ejemplo peraltado, el caso del rey de Castilla y Aragón, Carlos, Emperador del Sacro Imperio Romano de la Nación Alemana por elección de los Kurfürsten del Imperio. Aquí habria que agregar a Jellinek, por nuestra parte, que el casamiento puede conformar una Unión personal, como ocurrió justamente con Castilla y Aragón bajo Isabel y Fernando. No obstante, el

\footnotetext{
38 Jellinek Georg, Die Lehre von den Staatenverbindungen, op. cit., p. 87.

39 Consideraremos esta cuestión más abajo.

40 Jellinek Georg, Die Lehre von den Staatenverbindungen, op. cit., p. 213.

41 Cfr. Schmitt Carl, Verfassungslehre, Duncker \& Humblot, Berlin, 1993, pp. 370-379.
} 
principio dinástico de legitimidad es el que sustenta en casi todos los casos la formación de este tipo de monarquías compuestas. Del mismo modo -fuera del infrecuente supuesto de la elección o el matrimonio- es el principio dinástico el que da razón en el resto de los casos de la disolución del vínculo que une a los reinos. Así lo constata Jellinek: la Unión se disuelve cuando se extingue el derecho a una de las coronas o desaparece el sujeto legitimado para detentar ambas. Esto puede ocurrir o bien jurídicamente; o bien en el terreno de los acontecimientos políticos (faktisch), observa Jellinek. Cualquier circunstancia que haga periclitar ese derecho (muerte, destronamiento, abdicación, extinción de la dinastía) da por tierra con la Unión. ${ }^{42}$

Por el contrario, en la Unión real los reinos manifiestan su voluntad común en la designación de un único titular físico de la soberanía de ambos. Mas este titular físicamente único posee, si de una Unión real se trata, una pluralidad de personalidades jurídicas (i.e., una para cada reino); de poseer una sola personalidad jurídica, su imperio ya se ejercería sobre un Estado-complejo (Staatenstaat) o federal (Bundesstaat)-. Pues un órgano común resultaria contradictorio con la naturaleza de la Unión real, sostiene Jellinek, como hemos visto lo haría también Brie. ${ }^{43}$ Más allá de la comunidad jurídicamente establecida de monarca, la doctrina discute si, por debajo de la persona física del soberano, portadora de dos personalidades políticas distintas, hace al tipo de la Unión real la posesión de órganos comunes entre los reinos, abocados a asuntos también comunes. Kunz se pronuncia en contra; 44 mientras que García-Pelayo, recalando en el paradigmático caso de la unión de Austria y Hungría y en consonancia con una obra posterior de Jellinek, la Allgemeine Staatslehre, ${ }^{45}$ tiene a esta segunda nota, si no como esencial, sí por lo menos como "normal" en el tipo Unión real. ${ }^{46}$ Lo cual no empece que la Unión real, canónicamente, sea vista como constituida por reinos (Estados) independientes, que actúan a través de sus propios órganos y ordenamientos jurídicos. ${ }^{47} \mathrm{Y}$ que su nota esencial sea la comunidad -establecida por un instrumento jurídico contractual- de un monarca común, una identidad personal del titular que en principio no comportaría identidad (político-jurídica) de órganos. ${ }^{48}$

42 Jellinek aporta la cita de Grocio, quien ya había indicado que la cabeza común a varios cuerpos podia representar esa comunidad en tanto ostentase diversos respectos; y quien señala que la extinción de la casa reinante acarrea la reversión de los derechos de imperio a cada pueblo antes coaligado: "extincta domo regnatrice imperium ad quemque populorum seorsim revertitur" (De Jure belli ac pacis, Lib. I, cap III, 7, 2), citado por Jellinek Georg, Die Lehre von den Staatenverbindungen, op. cit., p. 87).

43 Jellinek Georg, Die Lehre von den Staatenverbindungen, op. cit., pp. 211-212.

${ }^{44}$ Kunz Josef, Die Staatenverbindungen, op. cit., p. 420; ver, con todo, p. 421.

45 Jellinek Georg, Allgemeine Staatslehre (trad. cast. F de los Ríos: Teoría general del Estado, Albatros, Buenos Aires, 1943), p. 610.

46 García Pelayo Manuel, Derecho constitucional comparado, op. cit., p. 206. Pero enseguida explica: "Sin embargo, desde el punto de vista político la comunidad de tales órganos no puede considerarse en modo alguno como accesoria, y sobre todo en una etapa en que la racionalización del poder disminuye la significación de la unidad del titular de la Corona para resaltar la de la estructura orgánica e impersonal de la organización estatal” (p. 207).

47 Kunz Josef, Die Staatenverbindungen, op. cit., p. 421.

48 Kunz Josef, Die Staatenverbindungen, op. cit., pp. 429-430. 
La nota jurídico-internacional de la Unión real que, con todo, dejaría subsistir en su seno a dos unidades politicas ha hecho surgir entre los especialistas la discrepancia acerca de si las relaciones exteriores son asunto común a ambos reinos, o no: es decir, si en el plano internacional hay un sujeto o dos. Kunz observa al respecto que la proveniencia cientifica de los especialistas no ha sido indiferente a su opción doctrinal, pues mientras los internacionalistas en general han decantado por atribuir subjetividad jurídico-internacional única a la Unión real, los teóricos del Estado han tendido a subrayar la independencia de los reinos involucrados, afirmando su plena subjetividad internacional. ${ }^{49} \mathrm{Kunz}$ sostiene que, desde el punto de vista jurídico, los fundamentos de las Uniones reales adolecen a menudo de lagunas. Ese rasgo institucional ha prohijado disensos y oposiciones políticas ad intra de estas formas de unión, además sostenidos en una serie de factores politicos, convergentes con la relativa incertidumbre que se puede suscitar respecto de sus contornos jurídicos. Así, señala Kunz, la frecuente asimetria de poder entre las partes unidas (que conlleva la posibilidad de que entrechoquen "politicas de hegemonía", por un lado, y "luchas por la independencia", por otro); y el hecho de que esas partes de la Unión real, al contrario de lo que ocurre con los Estados federales, consistan a menudo en naciones y pueblos diversos entre sí. ${ }^{50}$ En definitiva, la respuesta a la unidad o identidad del órgano encargado de las relaciones exteriores parecería quedar librada al caso particular de cada Unión real histórica. Es así como no han dejado de aparecer diversas situaciones y áreas de gobierno (como las relaciones exteriores, o la conducción de las fuerzas armadas) que han sido atendidas de variado modo. ${ }^{51}$ Sea como fuere, Kunz sostiene la tesis de que, aun sin ser esenciales a esta forma politica, en la Unión real se han hallado habitualmente, junto al monarca común a ambos reinos, órganos comunes encargados de atender asuntos también comunes por medio de actos jurídicos válidos para ambos reinos. Sólo que tales órganos -importante señalamiento éste- han tenido funciones administrativas y no legislativas. ${ }^{52}$ Con ello Kunz vendría a disipar la antinomia Estado/órgano exclusivo versus entidad no estatal/órgano compartido (que sería la posición propia de los teóricos del Estado), planteando una subjetividad jurídico-internacional emanada de la Unión real misma -y no dependiente de una forma federal de unión-.

En línea con lo últimamente dicho, cabe destacar en particular una observación del destacado internacionalista y iusfilósofo, cuya obra representa el último tratamiento extenso y sistemático de las Uniones monárquicas en perspectiva jurídico-política. Este señalamiento apunta a dos subclases o subtipos de la Unión real. Kunz distingue entre Uniones reales que representan uniones de Estados en sentido propio, "auténticas (echte)"; y otras que representan uniones de Estado en sentido impropio, o lato, "no auténticas (unechte)". Las primeras son las que supra se han venido caracterizando (las

49 La presentación exhaustiva de la doctrina respectiva de los autores la trae Kunz Josef, Die Staatenverbindungen, op. cit., pp. 422-426 de su obra.

50 Kunz Josef, Die Staatenverbindungen, op. cit., pp. 426-428.

${ }^{51} \mathrm{Kunz}$ Josef, Die Staatenverbindungen, op. cit., pp. 431-432. Este autor señala que el caso de Austria-Hungria es aquél en donde la zona de órganos y asuntos comunes ha sido más amplia, y Suecia-Noruega aquél donde dicho ámbito ha sido más restringido.

52 Kunz Josef, Die Staatenverbindungen, op. cit., pp. 433-435. 
canónicas): es decir, (a) uniones de reinos independientes que han entablado una relación de coordinación política, estructurada jurídicamente en un tratado; una unión que tiene entonces carácter jurídico-internacional (völkerrechtlich). Ahora bien -y esto es lo pertinente para nuestros desarrollos- Kunz reconoce la existencia de otras formas de Unión real, signadas por el carácter constitucional (staatsrechtlich) de su término ad quem: es decir, se trata de uniones celebradas ya sea (b.1.) entre un reino unitario y otra comunidad integrada en $-\mathrm{y}$ subordinada a- ese reino principal; ya sea (b.2) entre dos reinos que poseen plena subjetividad jurídico-internacional, pero renuncian a ella en el tratado de unión. Con este segundo supuesto (i.e., reinos unidos pacticiamente que hubieran renunciado a su soberanía), así como con el primero (i.e., un modo de descentralización de un reino unitario) el resultado es una Unión real como unechte Staatenverbindung. Se trata entonces, en (b), de Uniones reales que conforman estructuras constitucionales descentralizadas. ${ }^{53}$

\subsection{Sobre la raigambre de la Unión personal y de la Unión real como Uniones de reinos (y sobre su respectiva juridicidad)}

Se plantea en este lugar la cuestión de si la Unión personal y la Unión real, a pesar de su identidad en cuanto a la forma de régimen y su principio de legitimidad (monárquica-dinástico), constituyen especies próximas de un género común, el cual a su vez se hallaría incluido dentro del más amplio grupo de las Uniones de Estados. Esta cuestión de la comunidad genérica entre la Unión personal y la Unión real se aborda sin apelar a delimitaciones rigurosas de corte lógico-ontológico, sino más bien explorando la cercanía o comunidad tipológica entre ambas formas. Debe entonces traerse a cuento la supra mencionada posición de Brie, que sólo acepta como Unión de Estados a la Unión real, ${ }^{4}$ y que servirá para abrir la discusión al respecto. Si acudimos a Jellinek tenemos que la primera formaria parte de las uniones (Verbindungen) "histórico-políticas"; mientras que la segunda constituiria un capítulo privilegiado de las "uniones organizadas" dentro de las "uniones con carácter jurídico", junto con la confederación (Staatenbund) y el Estado federal (Bundesstaat). Tal la clasificación del maestro de Heidelberg. Antes de establecer la diferencia entre ambas formas, Jellinek sostiene la tesis de que la ley, en el plano del derecho político (interno), ni crea ni disuelve una Unión (real) de Estados. No los crea, desde el momento en que la ley, inclusive aquélla sancionada con mayorías agravadas (i.e., la ley constitucional), sólo se dirige a los miembros de la propia comunidad, a ella sujetos. Tampoco la disuelve, ya que una decisión unilateral no podría tener efectos jurídicos efectivos sobre los órganos del otro Estado y sobre éste como tal. La juridicidad de la unión de Estados no posee, pues, índole constitucional, sino que el rango del acto jurídico del cual depende su existencia y perduración tiene

53 Cfr. Kunz Josef, Die Staatenverbindungen, op. cit., pp. 418-419.

54 Brie Sigfried, Theorie der Staatenverbindungen, op. cit., pp. 60-61; parejo temperamento en Kunz Josef, Die Staatenverbindungen, op. cit., p. 250. 
carácter internacional: se trata por necesidad de un tratado (interestatal). En efecto, el obrar común de dos Estados implica el recíproco y respectivo acuerdo. 55

La inteligencia de la tesis de Jellinek sobre el carácter formalmente jurídicointernacional de la Unión real ${ }^{56}$ puede sin duda beneficiarse con una consideración del proceso que lleva a la conformación de estas uniones. Al respecto estimamos se debería distinguir (como ya lo hemos hecho supra, al destacar la aportación de Kunz) entre el terminus a quo y terminus ad quem del decurso que desemboca en la Unión real. En efecto, nada obsta a que el punto de partida de la unión lo sea una monarquía en vías de cierta descentralización - cierta, por cuanto afectaría sólo a sus grandes partes, y no al conjunto de los pueblos en ella integrados-, pero que culmina en una forma política dual (o plural) cuyas partes se convierten en auténticos reinos independientes (o no). Por su parte, aunque el instrumento jurídico final revista la naturaleza de un tratado entre reinos ya reconocidos como independientes, la situación política previa podria haber comprendido a sujetos que todavía no eran tales. Utilizando la terminología de Jellinek (pero alejándonos de su estricta posición): un terminus a quo "staatsrechtlich" no sería necesariamente óbice para un terminus ad quem eventualmente "völkerrechtlich". Respecto del argumento de Jellinek de que la ley constitucional sólo obliga a los miembros de la propia comunidad, debe observarse que la decisión disponiendo la unión puede haber emanado de una instancia que engloba a los dos sujetos de la unión, y que por ello obliga a ambos. Es así como una decisión político-constitucional -o sea, de derecho político interno- podría tener efectos jurídicos sobre los dos reinos y haber así creado la Unión real.

Dicho lo anterior, aduzcamos los elementos de juicio que provee Jellinek respecto de la eventual comunidad de ambas formas de Unión. Por un lado, como hemos anotado, para el maestro de Heidelberg la Unión real tiene un carácter jurídico que no reviste la Unión personal. Jellinek no se detiene a señalar las razones de la no juridicidad de la Unión personal si se la compara con la real, como sí lo hará Brie. Para éste la primera clase de unión no conlleva efectos jurídicos en el ejercicio del poder del Estado en cada uno de los reinos. Ahora bien, junto con la mención de la diversa raigambre de ambas formas ("históricopoliticas"/“jurídicas”), Jellinek le asigna carácter de Unión de Estados sólo a la Unión real. La razón estriba en que la Unión personal ni presupone ni conlleva una unidad de voluntades de los reinos involucrados, mientras que la real consiste precisamente en una voluntad coincidente, unida (übereinstimmende, geeignigte) -por parte de los reinos-. De allí que la Unión real sí consista en una "unión de los reinos mismos". 57 No hay, pues, observa Jellinek -acertadamente-, voluntad de unión entre los reinos en el caso de la Unión personal: los reinos mismos no han acordado constituir una monarquía compuesta, sino que el derecho dinástico vigente impone la comunidad personal (fisica) del monarca.

55 Jellinek Georg, Die Lehre von den Staatenverbindungen, op. cit., pp. 197-211. Nuestro autor discute y refuta la posición de Von Juraschek, quien asignaba rango constitucional a los instrumentos jurídicos basales de la Unión real.

56 En la cual no resultaría inverosimil detectar una posible impostación estatalista de la doctrina dominante, pues necesariamente para que hubiera Unión real debería haber desde el principio dos reinos selbsständige que pactan la unión.

57 Jellinek Georg, Die Lehre von den Staatenverbindungen, op. cit., p. 212. 
Podria objetarse el carácter no jurídico, a secas, de las Uniones personales, por cuanto con el criterio de Jellinek la juridicidad de una unión de Estados parecería asignarse exclusivamente al acuerdo voluntario expreso y actual por el que las partes se vinculan en el plano internacional, dejando asî a un lado la constitucionalidad (i.e., juridicidad) de la legalidad dinástica por la cual dos lineas sucesorias invisten a un mismo titular. Tal vez los presupuestos más fundamentales del maestro de Heidelberg -que redundarán en su connotado esquema de una teoría sociológica del Estado (Allgemeine Soziallehre des Staates) desgajada de la teoría jurídica del Estado (Allgemeine Staatsrechtslehre)_58 se manifiestan aquí estableciendo una cuestionable cesura en la juridicidad de ambas formas de unión. Por su lado Juraschek, en parejo sentido, había sostenido que no existe un instituto jurídico común que provoque la coincidencia de la corona en una única persona física; ello, unido a la presencia de reinos independientes, hace que se trate de una unión de Estados fáctica (tatsächliche), mas no juridica (rechtliche). 59

Sea como fuere de lo últimamente dicho, no deja de ser cierto que la Unión personal, estrictamente tomada, no es en sí misma una unión de Estados. Por lo cual, como observa Brie, la forma y la actividad del poder de cada uno de los reinos no se ve afectada por la unión: en ese sentido, es verdad también que la Unión personal no conlleva efectos jurídicos sobre las partes, cuya existencia politica en principio transcurriría como si la unión no hubiera tenido lugar. ${ }^{60} \mathrm{Si}$ se trata o no de unidades politicas que permanecen independientes es un tema que ameritaría algunas disquisiciones teóricas -como por ejemplo, según hemos apuntado supra, la de la imposibilidad de la guerra reciproca-; disquisiciones, por lo demás, no desvinculadas de la necesaria observación empírico-histórica de los casos concretos en que tales Uniones se verificaron. Cabría precisar, sintéticamente, que el aducido defecto o ausencia de juridicidad se da en la relación de unión misma, es decir que la unión en tanto tal no es jurídica, por más que los órdenes dinásticos casualmente confluyentes sí lo sean. En efecto, estos órdenes producen la investidura sucesoria operando en paralelo, sin un acto jurídico-internacional que los vincule entre sí. En esa línea aparece asimismo claro que la Unión personal no es unión de reinos, ni en sentido propio ni en sentido impropio. Lo cual no comporta negar -repárese bien- que tal comunidad de monarca no pueda llegar a producir consecuencias que a la postre

58 Allgemeine Staatslehre, op. cit., Lib I, cap. I.

59 von Juraschek Franz, Personal- und Realunion, Heymann, Berlin, 1878, p. 77, citado por Kunz Josef, Die Staatenverbindungen, op. cit., p. 247. Enseguida este mismo autor aclara el sentido de la atribuida "historicidad" de estas uniones: por supuesto que la misma persona física resulta convocada por dos órdenes jurídico-políticos (i. e., los de los reinos involucrados); pero ambos órdenes producen dicho efecto de modo entre sí jurídicamente independiente (Kunz Josef, Die Staatenverbindungen, op. cit., p. 250).

60 Nótese cómo la magnífica expresión de Juan de Solórzano en referencia a los reinos peninsulares de la monarquía hispánica de su tiempo (el de los Austria) echa luz sobre este status político-jurídico independiente -por lo menos en el ámbito interno- a pesar de la comunidad de monarca: "los reinos se han de regir y gobernar como si el rey que los tiene juntos lo fuera solamente de cada uno de ellos" (Solórzano Pereira Juan de, Política Indiana, edición de Francisco Ramiro de Valenzuela, Madrid, Mateo Sacristán, 1736, IV, XIX, 37). J. H. Elliot, comentando el paso respectivo, agrega a esta categoría de reinos los de Flandes, Sicilia y Nápoles (Elliot John, “ $A$ Europe of composite Monarchies”, op. cit., pp. 52-53). 
influyan en la existencia politica de los reinos involucrados, sobre todo cuando la asimetría de poder entre las partes se revela acentuada. 61

Adolfo Posada sostiene el temperamento antedicho, a la zaga de Jellinek: la Unión personal no es una unión de Estados en sentido jurídico. ${ }^{62}$ Por su lado, Garcia-Pelayo no se pronuncia sobre esta cuestión. Significativamente señala a la independencia de los reinos y a la correlativa diferencia orgánico-politica de la corona como notas propias de ambas formas de unión, si bien sostiene -como hemos visto supra- que la Unión real se caracteriza por la unidad de su política exterior, lo cual manifestaría un cierto grado de unión entre los Estados bajo un mismo soberano. 63

\subsection{Sintesis y conclusiones parciales}

\subsubsection{El problema de un género común}

Hemos planteado en escorzo las lineas fundamentales de las dos formas de uniones monárquicas, buscando simultáneamente dilucidar la pertenencia o no de ambas a un género (rectius: tipo) común. Respecto de esto último, cabría sintetizar una aproximación en las siguientes proposiciones: a) no tendría asidero distinguir a las Uniones personales como formas no jurídicas, o carentes de carácter jurídico, sino a condición de reducir la juridicidad a los modos pacticios expresos, más asimilables al derecho de los tratados propio del derecho internacional contemporáneo; b) en cambio, el hecho de que en estas uniones se produzcan -o no- adaptaciones y coordinaciones entre las partes en el plano constitucional; o que la forma y el ejercicio del poder ad intra y ad extra de los reinos se vean modificados en las Uniones reales, mas no en las Uniones personales, todo ello echa luz sobre la diferenciación de ambas formas de unión, y en un punto crucial: precisamente en el de si ambas constituyen una unión de reinos; c) si bien el que la lealtad (allegiance) de los súbditos de ambos reinos se deba a la misma persona física ${ }^{64}$ y el que estos reinos se hallen impedidos de hacerse la guerra, milita en pro de una cierta comunidad entre ambos; sin embargo no deja de ser cierto que la coincidencia radica básicamente en el caput regni. En esa línea, si paramos mientes en el decurso histórico que signó la vida de las Uniones personales constatamos que, en mucho casos, los reinos unidos no concluyeron -por lo menos en lo inmediato- en una concentración politica unitaria que disolviese su identidad juridica tradicional. Las Uniones personales de Castilla y Aragón, no obstante el peso político castellano, no trajeron como resultado el colapso del derecho aragonés, sino hasta la llegada de los borbones a los reinos de España, con su politica centrípeta y niveladora de barrenamiento institucional. Lo propio ha ocurrido con Escocia, incluso tras su unión (integración) en un solo reino con Inglaterra, a partir de 1707: el derecho escocés continuó vigente en todo aquello que no fuera objeto de derogación por el

61 Cfr. las interesantes notas de Kunz sobre el fin o disolución de las Uniones personales (Kunz Josef, Die Staatenverbindungen, op. cit., p. 251).

62 Posada Adolfo, Tratado de Derecho Politico, Victoriano Suárez, Madrid, 1923, t. I, pp. 196197.

63 Cfr. García Pelayo Manuel, Derecho constitucional comparado, op. cit., pp. 206-207.

64 Sobre este problema véase infra la posición de Coke en el caso "Calvin". 
parlamento británico, soberano único del nuevo Estado. ${ }^{65}$ En los dos ejemplos mencionados nos las habemos con reinos territorialmente contiguos. Ahora bien, la característica señalada se acentúa al tratarse de unidades politicas separadas geográficamente; así, Gran Bretaña y Hannover, en Unión personal desde 1714, siguen su existencia politica con total independencia a partir de 1837, cuando el derecho constitucional del pequeño reino alemán veta la accesión de Victoria en razón de su sexo. ${ }^{66}$ Una colisión constitucional idéntica, y con parejo -terminante- resultado político (la desvinculación), se dio asimismo entre el reino de Holanda y el gran ducado de Luxemburgo en 1890, que sin embargo no eran distantes sino contiguos. Pero también en ese caso, y a pesar de la influencia del reino mayor -que la inmediatez territorial no podia dejar de acentuar-, la identidad de la forma politica propia del reino menor (base de su ulterior independencia) se habia conservado.

A partir de todo lo dicho es razonable concluir que la Unión personal es Unión de reinos per accidens y no per se; sólo comparte con la Unión real la identidad en la forma de régimen, i. e., la monárquico-dinástica. Con lo cual sería lícito diferenciarlas como dos tipos diversos de formaciones políticas -por lo menos si se las reduce a sus perfiles típicos y se descartan los claroscuros y matices que puedan haber investido a algunas formaciones históricas concretas, en las que los limites de ambas formas se hayan superpuesto, transitoria o permanentemente-.

Una circunstancia histórica significativa debe ser señalada a la hora de aquilatar y confirmar la tesis de las Uniones personales como uniones de reinos per accidens, así como la consideración de las Uniones reales como modos de descentralización intrapoliticos avanzados. Se trata del hecho de que, por lo menos por regla general, sólo las Uniones personales involucraban a reinos geográficamente separados entre sí. Y, por el contrario, las Uniones reales se configuraron ante todo entre reinos $\mathrm{o}$ unidades políticas territorialmente contiguas.

\subsubsection{La Unión personal como forma tradicional tipica}

Se echa de ver que el tipo de la Unión personal representaría la forma de unión de Estados (reinos, aquí) más signada por la cosmovisión y los usos jurídico-políticos tradicionales - medievales o premodernos-. ${ }^{67} \mathrm{La}$ centralidad de

65 Vide infra, nota 76. Para la situación de Escocia tras 1707 cfr. Cruickshandks Eveline, "La unión de Escocia y el problema de la identidad nacional escocesa", en Las monarquías del Antiguo Régimen, ..., op. cit., p. 60 y ss.

66 Sobre Gran Bretaña y Hannover cfr. Riotte Torsten, "Transfer durch Personalunion: Großbitannien-Hannover 1714-1837”, Europäische Geschichte Online (EGO), 14/05/2012. URL: http://www.ieg-ego.eu/riottet-2012_de. [consultado el 15 de octubre de 2019].

67 "La independencia de los países [de la casa de Habsburgo en el Medioevo], a pesar de su unión en las formas antedichas [sc., derecho hereditario e investidura] era garantizada ante todo por los estamentos", indica Brauneder; y este modelo de poder se extendió en la primera modernidad, bajo la forma de una "unión monárquica de Estados estamentales" (Brauneder, op. cit., pp. 225-226). Karel Malý, a propósito de la corona bohemia en la temprana modernidad, hace parejo señalamiento de la relevancia de los estamentos y de su carácter de corporaciones administrativas investidas de subjetividad (público)-jurídica para la concepción de la monarquía como un régimen en el que la dinastía comparte la conducción con los Länder. Es significativo el hecho de que esta autonomía normativa, administrativa y jurisdiccional -que se vio disminuida 
la figura del soberano, la supraordenación y como autonomía de sus derechos dinásticos por sobre las unidades territoriales a las que rige, muestra a las claras el predominio del elemento personal a la hora de delinear los respectivos principios de legitimidad y obligaciones de obediencia. No en vano un especialista italiano, en las postrimerias del s. XIX, apuntaba sin ambages que no era del caso extenderse en distinciones sutiles respecto de la compleja naturaleza de la Unión personal, forma que tiende a desaparecer, dejando a cada Estado una configuración "normal y definitiva" (sic). ${ }^{68}$ De hecho, para el momento en que esto se estampaba apenas subsistian las Uniones personales de Holanda y Luxemburgo (hasta 1890) y la efimera de Bélgica y el Congo, que devendria en breve relación metrópolis/colonia (vide infra, III). 69

En cuanto a la condición monárquica de sus regímenes ("sólo los Estados monárquicos pueden unirse personalmente" ${ }^{70}$, dicho aspecto premoderno, como hemos visto, constituye una característica compartida por la Uniones reales. Se trata de una nota fundamental para comprender cómo pueden operarse uniones en el plano de la corona sin que ello comporte de suyo, necesariamente, la instauración de un órgano común a ambos reinos; y lo que es más decisivo aun: que dichas uniones no equivalgan a integración o accesión de un reino en otro. En tal sentido resulta extraordinariamente certera la conocida sentencia del gran jurista de Indias, Juan de Solórzano. Al referirse a las llamadas uniones aeque principaliter (denominación que él mismo adopta y que echa al ruedo de los tópos del derecho político monárquico), las cuales englobarian tanto a las uniones personales como a la reales, afirma: "lo más cierto es que también en este caso los Reynos se han de regir, y gobernar, como si el Rey, que los tiene juntos, lo fuera solamente de cada uno de ellos". ${ }^{71}$

\subsubsection{La Unión real como proceso de descentralización}

En el caso de las Uniones reales reviste peculiar interés recalar en el proceso que les da origen y que termina en su conformación. Ello en razón de que a menudo se ha tratado de procesos de descentralización politico-constitucional, ad intra de un reino, que dieron como resultado una forma de Unión real. Como

tras la insurrección checa y la derrota de la Montaña Blanca (1620), así como de resultas del proceso de centralización de la monarquía durante el s. XVIII- no llegó a corresponder al status de una Unión (personal, o real) con Austria (Malý Karel, "Die Verfassung des Staates der Böhmischen Krone", en Der Staat, Beiheft 16: Zusammengesetzte Staatlichkeit in der europäischen Verfassungsgeschichte, cit. supra, pp. 76 y ss.). Es decir que el régimen de autonomía y de participación de los estamentos en la cosa pública no dependía exclusivamente de la independencia del reino, sino que configuraba el estilo constitucional habitual de la temprana modernidad.

68 Cfr. Brunialti Attilio, Unioni e combinazioni fra gli Stati. Gli Stati composti e lo Stato Federale, Unione Tipografico-Editrice, Turín, 1891, pp. LIII y LVI.

69 Por su lado, al entrar el s. XX todavía existian dos Uniones reales, la de Suecia y Noruega y las de Austria-Hungría; y en 1918 aparecerá la de Islandia y Dinamarca. Otras uniones reales -en la temprana modernidad- lo fueron las de Lituania y Polonia (tratado de Lublín, 1569) y la de Dinamarca y Schleswig-Holstein (1460-1863).

70 Así lo remarca Kunz Josef, Die Staatenverbindungen, op. cit., p. 248, respaldado en los señalamientos de Jellinek, Brie, Anzilotti, Cavaglieri, Hall, Lawrence, Heilborn y Kelsen.

71 Solórzano Pereira Juan, Política Indiana, op. cit., L. IV, cap. 19, n 37. 
hemos visto, la especie de Unión real denominada "unechte Staatenverbindung" por Kunz cuenta como una de las variantes de sus dos subespecies a una forma de descentralización por la cual una monarquía concede a una de sus partes integradas un estatuto de unión, jurídicamente establecido, bajo la forma de un tratado -0 , más condicentemente con la naturaleza de una descentralización unitaria, bajo forma constitucional-, que norma una comunidad de monarca en cabeza del heredero legítimo de la dinastía reinante (en el reino principal). ${ }^{72}$ Esta forma de unión de reinos sería entonces impropia ("inauténtica"), ya no por defecto en la unión -como la Unión personal-, cuanto por defecto en la naturaleza de reino (independiente) que revisten los sujetos de la unión, antes de operada ésta, o incluso una vez operada. Se trataría, pues, de una Unión de reinos secundum quid, de la cual el primer y pleno analogado lo sería la Unión real entre reinos: la Unión real simpliciter. Por otra parte, repárese en que el instrumento jurídico que formaliza la vinculación ya no sería un tratado (interestatal), sino una disposición de orden político interno (constitucional).

\section{DOS EJEMPLOS HISTÓRICOS CLÁSICOS DE UNIÓN PERSONAL Y DE UNIÓN REAL. CONTEXTO HISTÓRICO Y DISEÑO INSTITUCIONAL FUNDAMENTAL}

\subsection{Inglaterra y Escocia}

A la muerte de Isabel I Tudor ( $† 24$ de marzo de 1603), quien había fallecido sin descendencia, ${ }^{73}$ Jacobo VI Estuardo, rey de Escocia desde el 29 de julio de 1567, accede al trono inglés como Jacobo I (25 de julio de 1603). ${ }^{74}$ Lo sucederán en ambas coronas su hijo Carlos I (1625-1649, destronado y ejecutado por la revolución de Cromwell); sus hijos Carlos II (1660-1685) y Jacobo II (1685-1688, destronado por su hija y yerno); éstos últimos: Maria (†1695) y Guillermo de Orange $(\dagger 1702)$; y por fin Ana, hija menor de Jacobo II (1702-1714 -reina de Gran Bretaña desde 1707-). ${ }^{75}$ En lo que sigue sólo se espigarán algunos de los

72 En realidad esta alternativa no había pasado inadvertida para el propio Jellinek, quien apunta que un modo posible de conformación de la Unión real se da cuando un Estado unitario se fracciona por un tratado en varios reinos, conservando a la misma persona como soberano común a sus partes (Jellinek Georg, Die Lehre von den Staatenverbindungen, op. cit., p. 220).

73 El cuadro de pretendientes con una evaluación de sus respectivos títulos para aspirar al trono lo trae Belloc Hilaire, Historia de Inglaterra, Dictio, Buenos Aires, 1980, pp. 359-360.

74 Jacobo I intentó llevar a cabo una unión que involucrara a los reinos mismos, al comienza de su reinado como monarca inglés, pero la iniciativa fue rechazada por el Parlamento en 1604 y 1605 (Wormald Jenny, "A Union of Hearts and Minds? The Making of the Union between Scotland and England", Revista Internacional de Estudios Vascos, $n^{\circ} 5,2009$, p. 122). La autora también resalta la relativa paridad de fuerzas y prestigio de ambas monarquías en el momento de la accesión de Jacobo I (p. 117) -la cual se desbalancearía a lo largo del siglo que lleva a la Unión de los reinos, anota Daniel Szechi (en "The Hannoverians and Scotland", en Conquest and Coalescence, op. cit., p. 119 y 126).

75 Existe, en efecto, un capítulo clave de la historia politica de los pueblos anglosajones durante estos siglos: es el referido a la supra mencionada Acta de Unión del $1^{\circ}$ de mayo de 1707 y su concreción política, consistente en la creación de un reino común a Inglaterra y a Escocia, el de Gran Bretaña, a partir de ese año. No nos ocuparemos de ese tema, si bien, como es obvio, el período de la Unión personal entre ambos reinos (1603-1707) constituye un antecedente politico, social y económico de primer orden para la unión de los reinos que tendría lugar un siglo después de la accesión de Jacobo al trono inglés. Una unión que resultó más anexión (de Escocia a Inglaterra) que unión de Estados, juzga Asch (vide Asch Ronald, "Die Stuart Monarchie als 
contados rasgos institucionales de la forma politica que tuvo lugar a lo largo del s. XVII bajo los Estuardo; y sólo se indicarán en nota los factores políticos y culturales más salientes que amojonaron la existencia de esa Unión.

El hecho de que la búsqueda de las instituciones comunes que le corresponden a una Unión entre coronas (i.e., a la Unión personal en tanto tal) arroje resultados exiguos es demostrativo del delgado calado constitucional propio de esa forma política. Lo cual se comprueba en este ejemplo histórico mejor que en otros (piénsese, por caso, en Gran Bretaña y Hannover), toda vez que aquí se trata de reinos contiguos, con una base poblacional y cultural no idéntica mas sí relativamente homogénea (lo cual no era óbice para la diversidad de sus sistemas jurídicos) ${ }^{76}$, sin barreras idiomáticas demasiado apreciables, ${ }^{77}$ con intereses políticos convergentes en sus clases dirigentes, ${ }^{78}$ con una confesión protestante mayoritaria común. ${ }^{79} \mathrm{Y}$ aun así la institucionalidad de la Unión qua Unión se reduce a pocos elementos.

La Unión de Inglaterra y Escocia fue objeto, esto es dable remarcarlo, de un no desdeñable tratamiento teórico en el momento mismo en que existía, y cuyo término de comparación en muchos casos lo fue el gran paradigma de la monarquía múltiple: la hispánica. ${ }^{80} \mathrm{El}$ marco de esta unión responde al modelo canónico. No hay órganos legislativos comunes: el parlamento de Westminster legisla para Inglaterra y el de Edimburgo lo hace para Escocia. ${ }^{81} \mathrm{Y}$ en cada uno de esos cuerpos la situación del rey es distinta: si el parlamento inglés se va

'composite monarchy': Supranationale Staatsbildung in Grossbritanien und Ireland im 17. und frühen 18 Jahrhundert", op. cit., p. 162).

76 Cfr. Maitland Frederic William, The Constitutional History of England, ed. Fisher, Cambridge University Press, Cambridge, 1955, p. 332. Y las tipicidades del derecho escocés, en lo que no ha sido objeto de derogación por la Parlamento británico, ha continuado distinto hasta nuestros dias (cfr. Asch Ronald, op. cit., p. 150).

77 Cfr. Wormald Jenny, "A Union of Hearts and Minds? The Making of the Union between Scotland and England", op. cit., p. 113.

78 Cfr. Szechi Daniel, “The Hanoverians and Scotland”, op. cit. pp. 130-131.

79 Lo cual convertía a los partidarios de esa confesión (en sentido lato: ya fuesen anglicanos ingleses o calvinistas escoceses) en aliados que promovian una misma causa ante el enemigo común de los "popists": sobre el tema protestante cfr. Asch Ronald, "Die Stuart Monarchie als 'composite monarchy': Supranationale Staatsbildung in Grossbritanien und Ireland im 17. und frühen 18 Jahrhundert", op. cit., pp. 145-148, 160 y 165-166; Szechi Daniel "The Hanoverians and Scotland", op. cit., pp. 117-118 y 124. Ya en tiempos de la última Estuardo, Ana, los protestantes escoceses supieron que la aceptación del candidato hannoveriano constituía la sola forma de evitar la restauración de los Estuardo católicos -cuyo heredero, Jacobo III, abogaba por la continuidad de la Unión personal (cfr. Robertson John, "The Conceptual Framework of AngloScottish Union", Revista Internacional de Estudios Vascos, n 5, 2009, p. 128; Szechi Daniel, "The Hanoverians and Scotland", op. cit., p. 122). Jacobo III era el pretendiente dinásticamente legítimo; a él el Parlamento inglés, nuevo titular del poder, le opuso "la casa de Hannover, la número cincuenta $\mathrm{y}$ ocho en la línea de sucesión hereditaria, pero también la heredera protestante más cercana", señala Cruickshandks Eveline ("La unión de Escocia y el problema de la identidad nacional escocesa", op. cit., p. 58).

80 Cfr. Arrieta Jon, "Forms of Union: Britain and Spain, a Comparative Analysis", Revista Internacional de Estudios Vascos, $\mathrm{n}^{\circ}$ 5, 2009, pp. 23-52; sobre el tono predominantemente teorético de estas obras vide Wormald Jenny, A Union of Hearts and Minds? The Making of the Union between Scotland and England, op. cit., pp. 110-111.

${ }^{81}$ Maitland Frederic William, The Constitutional History oh England, op. cit., p. 331. 
convirtiendo a lo largo del siglo en el reducto institucional de los grandes terratenientes y de la gentry, opositores del trono; al contrario el rey pudo contar hasta 1688 (excepción hecha, claro está, del período que se inicia con la revuelta contra Carlos I y continúa con Cromwell) con la aquiescencia del parlamento escocés, presto a concederle hombres y fondos. ${ }^{82}$ Por su parte el Privy Council inglés, órgano supremo también jurisdiccional -incluso era última alzada para las Plantations norteamericanas, en lo demás prácticamente autónomas en ese ámbito- no tenía jurisdicción sobre Escocia. ${ }^{83}$ Otro influyente órgano de consejo, la cámara real (Bedchamber), contó habitualmente con la presencia de miembros escoceses, que jugaron un papel importante en los avatares de la relación del soberano con Escocia (la cual pasó por un momento trágico bajo Carlos I). ${ }^{84}$ Por lo demás, Escocia tenía su propio consejo privado, así como un comité de los artículos, que recibía instrucciones de la corona respecto de las disposiciones que debian tratar los estados (básicamente, los nobles reunidos en una cámara, sin participación del tercer estado, reducido a la discusión de asuntos menores). ${ }^{85}$

Así pues, y respecto nada menos que del gobierno, la unión que nos ocupa tampoco desdecía los cánones clásicos. Uno de los problemas clave de las monarquías múltiples -puntualiza Elliot en línea con Russel-86 radica en la orfandad en que suele quedar el reino menor a causa de la residencia del rey en el reino principal. Tal problema parece haberse visto amortiguado en el caso anglo-escocés. El rey gobierna directamente ambos reinos. Jacobo I -quien traslada la dinastía a Londres, como su capital natural- no obstante ostenta con satisfacción el hecho de que él gobierna su patria sin necesidad de soldados o intermediarios ("Here I sit and gouerne it with my Pen, I write and it is done and by a Clearke of the Councell I gouerne Scotland now, which others could not doe with the sword"); 87 y los estamentos le reconocen que Escocia no es tratada como país esclavo o conquistado, a través de un comisionado o de un virrey. ${ }^{88}$ Con todo, es verdad que a partir de la restauración las condiciones del régimen se endurecieron en todos los dominios de la monarquía Estuardo;89 y que el esquema institucional entró en una cierta crisis, sacudido por los movimientos políticos y su trasfondo religioso. De tal modo, por ejemplo, una decisión de la

82 Szechi Daniel, “The Hanoverians and Scotland”, op. cit., p. 121.

83 Cfr. Asch Ronald, “Die Stuart Monarchie als 'composite monarchy': Supranationale Staatsbildung in Grossbritanien und Ireland im 17. und frühen 18 Jahrhundert“, op. cit., p. 156.

84 "Para Escocia el Bedchamber fue el medio esencial para afrontar el problema del rey ausente", expresa Conrad Russel ("Gran Bretaña a comienzos del s. XVII: monarquía compuesta y reino múltiple”, op. cit., pp. 38-39).

85 Cfr. Ogg David, “Inglaterra después de la restauración”, en Carsten F. L. (edit.), The New Cambridge Modern History, Sopena, Barcelona, 1979, t. V, p. 230.

86 Cfr. Elliot John, “A Europe of composite Monarchies”, op. cit., pp. 55-56.

87 Discurso al Parlamento de marzo de 1607 (en The Political Works of James I, ed. Ch. H. McIlwain, Cambridge, Harvard University press, 1918, p. 301).

88 Robertson John, “The Conceptual Framework of Anglo-Scottish Union”, op. cit., p. 126.

89 Así ocurrió también en las colonias norteamericanas (cfr. Greene Jack, The Constitutional Origins of the American Revolution, Cambridge University Press, Nueva York, 2011, pp. 13-15). 
trascendencia del Act of Settlement (1701) se tomó sin consultar al parlamento escocés. 90

No finalizaremos esta escueta revista sin mencionar el célebre caso "Calvin", fallado por el King's Bench - protagónicamente integrado por el juez Coke- en 1608.91 En él se discutía el derecho de un escocés nacido tras la coronación de Jacobo I a heredar tierras en Inglaterra, cuyas leyes impedian a los extranjeros devenir propietarios en el reino. Coke defiende la pretensión del postnatus, argumentando que la distinción de reinos no le impedía hallarse bajo las leyes de Inglaterra. Es verdad que seguía tratándose de dos reinos distintos, pero el hecho de que el soberano fuese desde 1603 (año de la coronación de Jacobo VI Estuardo de Escocia como Jacobo I de Inglaterra) la misma persona física tornaba al escocés Calvin un "no extranjero (not alien)" en el reino de Inglaterra. Es decir que la allegiance a la persona de Jacobo VI de un escocés nacido tras su accesión al trono de Inglaterra -obediencia y lealtad fundada no en la ley positiva de un reino sino en la ley natural y divina- implicaba que ese súbdito escocés adquiría las obligaciones y los derechos que generaba la potestad de Jacobo, como los derechos de dominio sobre el suelo inglés. ${ }^{92}$ Tal la sintesis del fondo del asunto de "Calvin", cuya resolución no deja de provocar algunas perplejidades respecto de su coherencia con la distinción principial -del propio juez Coke- entre la persona natural del rey y sus varias capacidades politicas: "una capacidad politica para el reino de Inglaterra y otra para el reino de Escocia", había sostenido Coke. ${ }^{93}$ Salvo que los derechos de propiedad se entendieran como fundados en la ley natural y divina, las mismas que sustentaban la lealtad a la persona del soberano.

\subsection{Austria y Hungria}

El caso de Austria y Hungría constituye el ejemplo sin duda paradigmático de Unión real. Dos cuestiones son centrales, señala Jellinek, para determinar la naturaleza político-constitucional de esta unión: si ambos reinos son o no soberanos; y si sobre ellos se yergue un poder central del que los reinos reciben sus derechos, y que podría despojarlos de ellos. La primera pregunta, para el autor, no ofrece dudas: los reinos son soberanos. Respecto de la segunda, Jellinek cree necesario fundamentar la respuesta negativa, y lo hace recurriendo a la historia de Hungría. La Pragmática Sanción de 1722/23, en efecto, habia dispuesto que en caso de extinguirse las lineas masculina y femenina de la Casa

\footnotetext{
90 Cfr. Arrieta Jon, "Forms of Union: Britain and Spain, a Comparative Analysis", op. cit., pp. 4950.

91 Para lo que sigue Coke Edward, The seventh Part of the Reports of Sir Edward Coke, sin datos de la editorial, Londres, 1608, \& 10 a y ss.

92 Lo cual, sin embargo -nótese-, no se hacía extensivo a la validez de los títulos de nobleza en el otro reino (Coke Edward, The seventh Part of the Reports of Sir Edward Coke, op. cit., \& 15 a). La condición de par del reino conllevaba la membrecía de la Cámara de los Lores y, siendo que ambos reinos permanecian distintos y regidos con sus propios ordenamientos legales y órganos de gobierno, un noble escocés no podía pasar a ser miembro de la cámara alta del órgano supremo de legislación de Inglaterra, sólo subordinado al rey. Por lo demás, la allegiance a la persona natural común del rey no se extendía al goce del título de nobleza -instituto creado por la persona politica del soberano, persona propia de cada reino en particular-.
}

93 Coke Edward, The seventh Part of the Reports of Sir Edward Coke, op. cit., 10 a. 
de Habsburgo -herederos legitimos, pero que a su condición de tales deberian unir la confesión católica-, el reino de Hungría tendría derecho a elegir un rey. Esa disposición, por lo demás, formó parte del Compromiso (Ausgleich) de 1867 (en su \& 2), el instrumento jurídico que constituyó la Unión real. La posibilidad de tal disolución mostraba, concluye Jellinek, que no había existido ni existía un Estado común del que ambos reinos fueran parte, ni menos que Hungría no fuera sui iuris frente a Viena. Siendo esto así, y no existiendo entonces una potestad jurídica común (Centralgewalt), luego sus relaciones con "los reinos y países representados en el Consejo Imperial" (el nombre con que se denominaba a todo lo que en la monarquía dual no era Hungria) no podian sino consistir en un tratado (Vertrag). ${ }^{94}$ Hasta aquí, Jellinek.

Al gran teórico del Estado le interesa abogar por el status independiente del reino húngaro bien antes del momento del Ausgleich: con la Pragmática -que no creó un nuevo Estado, sostiene Jellinek-, una ley vinculante sobre la sucesión a la corona de San Esteban había emanado del rey de Hungría con el acuerdo de los estados del reino. Por la misma razón esa ley no podía obligar sino al reino de Hungria, pues de lo contrario habría provenido de un órgano central a ambos reinos. De todas maneras, tanto la Pragmática cuanto la ulterior interpretación del Ausgleich pactan con los otros reinos de la monarquía una común heredad, indivisible e indisoluble. Jellinek describe así la decisión dual de la Pragmática: dos reinos hasta entonces jurídicamente -aunque no "históricamente" (sic)independientes, encabezados ambos por la misma persona física, pactan constituir una sola potencia en el ámbito internacional. El monarca tendrá dos personalidades distintas, la de rey de Hungría y la de señor del resto de los reinos y países, con lo cual el único órgano central lo es el soberano común. Se trataba ya en 1723, concluye Jellinek, de una unión jurídico-internacional, de una Unión real 95. Así pues, según Jellinek el Acuerdo de 1867 no habría sido sino la continuidad -exceptuado el hiato de los intentos unitarios de Viena de la primera mitad del s. XIX- de las disposiciones de la Pragmática Sanción, las cuales a su vez habrian reconocido la independencia "jurídica, no histórica" de Hungria. Ahora bien, la salvedad por el propio Jellinek de una independencia que era jurídica pero no histórica trasunta la realidad política objetiva de la nación húngara (dependiente del poder del Emperador del Sacro Imperio) y su carencia de títulos para erigirse en contraparte de un verdadero tratado jurídicointernacional. 96

Dirimir siquiera brevemente la cuestión del status politico del Imperio y de Hungria en los estadios anteriores al Ausgleich parecería exceder del objeto de este apartado. No obstante -dado que hemos presentado supra una alternativa "no canónica" sobre este tipo de unión (la cual cotejaremos con el presente caso histórico), y dados los aspectos prima facie cuestionables del planteo de Jellinekno será impertinente intentar delinear la situación de los actores (Viena y Hungría) en los prolegómenos del Ausgleich. Tras el breve período de la conmoción revolucionaria de 1848, la derogación de la posterior constitución

94 Cfr. Jellinek Georg, Die Lehre von den Staatenverbindungen, op. cit. , pp. 234-236.

95 Jellinek Georg, Die Lehre von den Staatenverbindungen, op. cit., pp. 238-240.

96 Kunz resalta la inviabilidad de considerar tratado jurídico-internacional a la Pragmática Sanción (Kunz Josef, Die Staatenverbindungen, op. cit., p. 410). Como tampoco el Ausgleich fue un tratado, sostiene asimismo allí Kunz (Kunz Josef, Die Staatenverbindungen, op. cit., p. 410). 
imperial de 1849 (en 1851) y el violento sofocamiento del intento independentista húngaro (1849), el Imperio conoció una nueva etapa institucional, en la que los derechos históricos fueron cobrando prevalencia. ${ }^{97}$ Lo cual no fue óbice para que desde Viena también se instalara una política de centralización burocrática y germanizante, apoyada asimismo en la jerarquía católica (concordato de 1855, que rompe con el "josefinismo"). Con su constitución de 1848 derogada, los húngaros, convocados por el culto de sus derechos tradicionales y por el simbolismo de la corona de San Esteban -superior a monarcas y dinastías transitorias-, se constituyeron en el núcleo irreductible de las resistencias nacionales a Viena. A partir de octubre 1860 se suceden una serie de modificaciones en la estructura de poder del Imperio. El Reichsrath, consejo de la corona, pasa a ser una cámara consultiva (un "verstärker Reichsrath", con representantes de todo el Imperio) y se implementan medidas de descentralización administrativa y legislativa atendiendo al criterio de los derechos históricos. Al pedido de reforma constitucional de la mayoria "federalista" del Reichsrath el Emperador responde con un diploma (20 de octubre) en el que promete "armonizar los deseos de mis países y mis pueblos, sus convicciones y los derechos que reclaman, y las necesidades reales de la monarquía". 98 A pesar de las esperanzas puestas en estas reformas, el Emperador deroga el diploma del año anterior y sanciona una nueva constitución, de espíritu unitario (1861). Antes de eso, tras una enérgica manifestación de la dieta húngara recordando el "tratado fundamental" celebrado por el reino en 1723 con la dinastía, un rescripto imperial había declarado que trescientos años de gobierno creaban un nexo mucho más estrecho que una mera unión personal y derogado la constitución de 1848 -que Hungría había restablecido, y con cuya vigencia, en efecto, el único nexo con Viena hubiera sido la persona del monarca-. A partir de allí, la oposición húngara, acaudillada por Ferenc Déak, no cejará en su puja por lograr un reconocimiento constitucional del peculiar lugar que su patria ocupaba en el Imperio. Aunque los magyares no son los únicos: checos, croatas, eslovenos, polacos y rumanos (las principales naciones eslavas del Imperio) plantean reivindicaciones análogas, si bien no todos rechazan enviar diputados al Reichsrath, como si lo hace Hungría. Tras la suspensión de la constitución por el Emperador (1865), Richard Belcredi, ministro de Estado que asume el cargo en vísperas del conflicto con Prusia, estima justo no hacer una sola concesión (i.e., a Hungria), sino atender las del resto de los pueblos eslavos de la monarquía. Esto planteaba un potencial escenario de corte federal. Pero la derrota de Sadowa (con el consiguiente temor por la actitud húngara frente a una invasión prusiana) precipita los acontecimientos; y Belcredi deja el ministerio, que ocupa Beust. Finalmente, Viena decide circunscribir su apertura políticoconstitucional al pueblo húngaro: quedará así conformada la monarquía dual.

97 Brauneder Wilhelm, "Die Habsburgermonarchie als zusammengesetzter Staat”, op. cit., pp. 218-221.

98 Hauser H., Maurain J., Benaerts P., L'Huillier F., Du libéralisme à l'imperialisme (1860-1878), P. U. F., París, 1952, „Réforme et nationalité dans l’Empire Habsbourgeois“, pp. 83-84; resulta siempre útil la clásica sinopsis de Seignobos Charles, Histoire politique de l'Europe Contemporaine. Évolution des partis et des formes politiques, Armand Colin, París, 1897, pp. 390-401. 
Sellado el Ausgleich, el 8 de junio de 1867 Francisco José ciñe en Budapest la corona de San Esteban. 99

Por mor de brevedad, haremos en lo que sigue una prieta sintesis de la estructura político-constitucional de dicha monarquía dual. ${ }^{100}$ Con arreglo al Ausgleich el hasta entonces Imperio Austríaco se convierte en Monarquía AustroHúngara. Su soberano será en adelante Emperador de Austria y Rey Apostólico de Hungria. ${ }^{101} \mathrm{El}$ Compromiso se expresa en dos leyes de contenido acorde pero no idéntico, emanadas de cada uno de los reinos unidos (es decir, de actos legislativos distintos). Habrá materias comunes, que se resuelven por gestión común, a saber las relaciones exteriores, el derecho de legación y la representación comercial -aunque los tratados exigirán aprobación por cada parlamento-; los asuntos militares; y la hacienda necesaria para atender las dos áreas antedichas. Estos asuntos comunes se conducen, en lo gubernativo, con ministerios comunes; en lo legislativo, con delegaciones nombradas por los parlamentos, que deliberan por separado -salvo en caso de desacuerdo, en el que se reunirán en cámara única. Habrá asimismo materias no comunes, que se tratarán según criterios idénticos: legislación aduanera; legislación impositiva sobre la producción industrial; el sistema monetario y los ferrocarriles de interés recíproco. Los criterios idénticos se establecerán de dos modos: o bien a), los ministros del área preparan proyectos que son tratados por las delegaciones, las cuales preparan resoluciones concordantes a ser presentadas ante el monarca; o bien b), las delegaciones eligen una diputación común que prepara un proyecto, el cual, una vez aprobado por cada una de ellas, termina siendo presentado al soberano.

A juicio de Brauneder la monarquía dual constituye el desemboque natural de la concepción político-constitucional que antecede al Ausgleich. Ahora bien, el punto de arranque del proceso que condujo a esa forma monárquica es un reino unitario: en 1848 el Imperio es un Einheitsstaat. Predominaba una institucionalidad monárquico-unitaria, si bien descentralizada, con un soberano único para todos sus dominios; había un Emperador de Austria, pero no, por ejemplo, un rey de Bohemia, si por tal se entiende una auténtica corona -con consecuencias constitucionales-. A partir de esa constitución imperial y en continuidad con el carácter ya estatal de la constitución húngara de 1848 tiene lugar el Ausgleich de 1867. La monarquía compuesta por dos Estados (ZweiStaaten-Monarchie) resulta así "una consecuencia de ese pensamiento monárquico-unitario", apunta Brauneder. ${ }^{102}$

Digamos por nuestra parte que tal concepción no había provocado un aplanamiento uniforme a la manera del Estado contemporáneo, puesto que el

99 Hauser H., Maurain J., Benaerts P., L'Huillier F., „Réforme et nationalité dans l'Empire Habsbourgeois“, op. cit., pp. pp. 81-92; Seignobos Charles, Histoire politique de l'Europe Contemporaine, op. cit., pp. 493-501.

100 Cfr. García Pelayo Manuel, Derecho constitucional comparado, op. cit., pp. 206-209.

101 Resulta significativo que todo el territorio que no pertenecía a Hungría (i.e., el Imperio propiamente austriaco) careciera de nombre oficial: se le denominaba "Die in Reichsrath vertretenen Königreiche und Länder". No se correspondia, pues, su jurisdicción con una única entidad política o histórico-nacional. "Austria" parecía develar así un destino histórico anclado en su papel de quicio y cabeza de un Imperio plurinacional.

102 Brauneder Wilhelm, op. cit., "Die Habsburgermonarchie als zusammengesetzter Staat", pp. 234-235. 
modo tradicional pervivió en el espíritu del Imperio, antes y después del Ausgleich; pero sí comportó que dentro de cada una de las unidades políticas integradas en la monarquía dual no se dieran otras uniones monárquicas. El caso de la corona de San Wenceslao es ilustrativo en lo que toca a Viena: desde la reforma teresiana en el s. XVII hasta la liquidación del Imperio tras la Primera Guerra el reino bohemio no poseyó órganos políticos propios. ${ }^{103}$ En lo que toca a de Budapest, puede aducirse el ejemplo de la nación croata. A pesar de su voluntad autonómica y de su históricamente acrisolada identidad, no hubo una unión análoga entre Hungría y Croacia a la que existía entre Austria y Hungría. ${ }^{104}$ En este caso, así como en relación con la mencionada "falta de nombre" de los territorios austríacos resulta de gran interés la lectura de la clásica tesis de Charles Eisenmann. Respecto de lo primero, Hungria maniobró para neutralizar las reivindicaciones de los pueblos eslavos y capitalizar sólo para sí la apertura política concedida por Viena; y, una vez producido el Compromiso, se ocupó de contener los reclamos de las naciones de ese origen bajo jurisdicción húngara. Respecto de lo segundo, el Ausgleich convirtió a Hungría en el poder preponderante dentro de la monarquía dual. ${ }^{105}$ En esa línea Kunz, por su lado, agrega que la deriva independentista que fue manifestando la politica institucional de Hungría habría llevado a la postre a la disolución del vínculo con Viena. ${ }^{106}$

¿Qué conclusión se obtiene, pues, frente a la monarquía dual, el caso histórico paradigmático de Unión real? ¿Responde la monarquía dual al esquema canónico defendido por Jellinek, el de una unión de reinos soberanos pactada en un tratado interestatal? La respuesta, seguramente, ha de ser negativa. El Ausgleich fue un caso de descentralización politica interna, concedido al pueblo húngaro a causa de su tesón incansable y de su férrea personalidad colectiva, moldeada en derredor de un símbolo extraordinario, la corona de San Esteban. Lo cual no quita a la solución llevada adelante por la Casa de Habsburgo nada del mérito inherente a la empresa de recrear -en las postrimerias del s. XIX-, por

103 Malý Karel, op. cit., “Die Verfassung des Staates der Böhmischen Krone”, p. 83.

104 Cfr. Cepulo Dalibor, "Entwicklung der Regierungsinstitutionen des Königreiches Kroatien und Slawonien (von 1868-1918)", en Mathé Gabor y Mezey Barna (edit.), Kroatische-Ungarische Öffentlich-Rechtliche Verhältnisse zur Zeit der Doppelmonarchie, Eötvös Universitätsverlag, Budapest, 2015, pp. 31-103. La investigación citada contradice el temperamento de la contundente obra del contemporáneo catedrático croata Pliveric Josef, Beiträge zum UngarischKroatischen Bundesrechte. Rechtliche und politische Erörterungen, Hartman Verlag, Agram, 1886, esp. pp. 31-130. Sin embargo, los claroscuros del status croata (reconocidos por Brie Sigfried, Theorie der Staatenverbindungen, op. cit., p. 70), a pesar del Ausgleich de 1868, decantan seguramente hacia una situación de provincia descentralizada para Croacia. En el mismo sentido general de Cepulo se pronunciaba Eduardo Llorens en 1932 (La autonomía en la integración politica. La autonomía en el Estado moderno. La autonomía de Cataluña. Textos parlamentarios y legales, Reus, Madrid, 2008, pp. 34-36). Otro escenario dudoso lo ofrece la vinculación politica ruso-finesa. En este caso nos inclinariamos a reconocer condición de Unión real a esa vinculación -si bien con sucesivos avances del poder San Petersburgo- hasta el proceso de rusificación iniciado bajo Nicolás II (sobre la unión de Rusia con Finlandia cfr. el valioso estudio históricojurídico de Bornhak Conrad, Russland und Finland. Ein Beitrag zu der Lehre von den Staatenverbindungen, Duncker \& Humblot, Leipzig, 1900).

105 Cfr. Eisenmann Charles, Le Compromis Austro-Hongrois de 1867 -Étude sur le dualisme-, Georges Bellais, París, 1904.

106 Cfr. Kunz Josef, Die Staatenverbindungen, op. cit., p. 414. 
lo menos para los dos reinos, una forma institucional que llevaba la impronta de una tradición política ilustre.

Ahora bien, surge inmediatamente, por último, la cuestión de si acaso el tipo canónico se ha verificado en alguna de las Uniones reales de los dos últimos siglos. Cabría responder afirmativamente: la Unión real de Suecia y Noruega (1814-1905) -si no se pretende una adecuación perfecta a conceptos jurídicos claros y distintos- respondió al tipo de unos reinos en principio independientes que continúan como tales hasta la resolución voluntaria y no conflictiva de sus vínculos políticos.

\section{ALGUNOS MODOS SUI GENERIS O IMPROPIOS DE LA UNIÓN PERSONAL: CONFORMACIÓN A PARTIR DE LA CONQUISTA, DOMINIO O PATRIMONIO DEL MONARCA; LA COMMONWEALTH}

Históricamente se han dado modos de vinculación monárquica de tipo personal en los que la intersección entre dos líneas hereditarias se debió a la acción consciente del titular del reino principal. En efecto, en ciertas ocasiones, los sujetos de la unión no en ambos casos preexistían a la unión. Es decir que una de las coronas (o la corona) de algún modo había creado su contraparte, por ejemplo a partir de la conquista de un dominio territorial -tuviera éste rango de reino, o no-. Tal dominio, así unido a la corona, tenía luego como soberano -o señor, o propietario- legítimo al monarca del reino principal, sin por ello integrarse total o parcialmente dentro del reino de éste (cuyo príncipe había originado la unión). La doctrina tiende a considerar algunos de estos vínculos como modos de Unión personal. Veamos algunos ejemplos concretos, comenzando por aquél que sólo reviste la apariencia de una Unión personal, no obstante manifestar rasgos significativos para la configuración del status de la corona como sujeto de derechos patrimoniales.

\subsection{E1 Ducado de Lancaster y la corona inglesa}

La apropiación de este señorío por Eduardo IV de York dio lugar a un precedente jurídico y político del mayor interés para las ulteriores disquisiciones teóricas -y decisiones institucionales- de los jueces y de los monarcas en los ss. XVI, XVII y XVIII. ${ }^{107}$ El ducado había pertenecido originariamente a los Lancaster antes de su accesión al trono de Inglaterra, y desde 1399 Enrique IV, con aval del Parlamento, lo había conservado como su patrimonio personal hereditario, independiente de su status de rey. Cuando Eduardo accede al trono en 1461, a la caida de la casa de Lancaster, decide incorporar el Ducado de su rival (a quien había destronado y despojado de todos sus bienes por alta traición), constituyéndolo a la manera de un patrimonio real hereditario. El ducado

\footnotetext{
107 Se trató -sostiene Kantorowicz, cuya exposición seguiremos para este punto- de un "caso a raíz del cual los jueces Tudor produjeron las más sorprendentes formulaciones relativas a los 'dos cuerpos del rey'. Puesto que estas formulaciones pasaron finalmente a manuales jurídicos y diccionarios tales como el de Crompton, Kitchin o Cowell y quizá también a los de otros autores de alrededor de 1600; y puesto que fueron citadas por autoridades como Coke, Bacon y posteriormente muchos otros, como por ejemplo Blackstone, es evidente que penetraron muy rápidamente en el lenguaje politico y popular, y que fueron repetidas una y otra vez" (Kantorowicz Ernst, Los dos cuerpos del rey, Alianza, Madrid, 1985, p. 379).
} 
confiscado, por una Act of Parliament, pasó así a formar parte de la heredad de la corona de Inglaterra: todos los monarcas del reino, comenzando por Eduardo IV, irian a poseerlo. Por derecho de la corona (pues el rey no tenía otros títulos para apropiárselo) la sucesión de los reyes ingleses adquirió la propiedad exclusiva y en bloque de los feudos, castillos, señoríos y pueblos que componían el ducado de Lancaster, cuyos beneficios revertirian sobre el príncipe en el trono. En la terminología anglosajona, el ducado se convertía en una corporation, una sociedad o persona jurídica, usufructuada por los reyes en tanto reyes y separada del reino: "aquellos tres [los reyes lancastrianos] lo poseian en su cuerpo natural diferente de la corona y el cuarto [Eduardo IV] en su cuerpo político por derecho de la corona y separado en la orden y gobierno de la corona, y no de otro modo", expresan los Reports, de Plowden. ${ }^{108}$ Es asi como hoy en día los bienes del Ducado de Lancaster representan la fuente principal del Privy Purse, la renta de la casa real británica. Pero el Ducado, como señorío, dejó de existir cuando Eduardo IV lo constituyó en una suerte de propiedad hereditaria de la corona. Así pues, este caso, en realidad, no ejemplifica un modo posible de Unión personal: sólo de extensión de los derechos dominiales de la corona sobre un territorio que queda de algún modo separado del reino.

\subsection{E1 Ducado de Lauenburg y Prusia}

La breve historia del Ducado en su unión con el rey de Prusia es manifestativa de la vigencia de rasgos definitorios del orden politico tradicional en períodos ya avanzados de la época contemporánea. En los acuerdos preliminares de paz del $1^{\circ}$ de agosto de 1864 , que puso fin a la guerra entre Austria/Prusia y Dinamarca, el rey de Dinamarca cedió a las potencias vencedoras el Ducado de Lauenburg. Esta disposición se confirmó en el tratado del 30 de octubre, por el cual Christian IX renunció a sus derechos a favor del Emperador y del rey de Prusia. Simultáneamente con ello, la Asamblea estamental de Lauenburg dirigió al rey de Prusia la petición de unión bajo un mismo monarca y con la garantía del mantenimiento de la independencia del ducado y de la vigencia de su propia constitución. El rey de Prusia vio de buen grado la posibilidad de una Unión personal; y fue así como en la Convención de Gastein del 14 de agosto de 1865 el Emperador renunció a sus derechos de condominio a favor del rey prusiano, a cambio de una suma de dinero. Dicha unión tuvo lugar a partir de 1866 y por un lapso de diez años. ${ }^{109}$ De hecho, lo que hubo fue una investidura de Guillermo I como duque de Lauenburg; al unir así este título al de rey de Prusia, el monarca pasó a utilizar oficialmente en el ducado la fórmula "Nos, Guillermo, por la gracia de Dios Rey de Prusia y duque de Lauenburg ...”. Guillermo fue el último duque

108 Kantorowicz Ernst, Los dos cuerpos del rey, op. cit., pp. 377-380.

109 Cabe mencionar que Jellinek la considera una Unión real (Jellinek Georg, Die Lehre von den Staatenverbindungen, op. cit., pp. 221-222); y que algunos autores (como Franz Bornhak: Abhängingkeitsverhältnisse, p. 67, citado por Wagner, vide infra) la han visto como una incorporación incompleta del ducado en el reino. El tema de la alzada jurisdiccional de Lauenburg no deja de tener interés respecto de su status politico-jurídico: la cámara de apelaciones estaba en Kiel y el tribunal superior de apelaciones (el "Ober-Appellationsgericht" surgido en tiempos de la Confederación Germánica y que hacía las veces del antiguo tribunal del Imperio, como tercera instancia), en Berlin. Sin embargo, ambas delegaciones jurisdiccionales habian sido determinadas por actos legislativos de la propia Asamblea de Lauenburg. 
de Lauenburg. Es verdad que al ducado le correspondió, dentro del gobierno prusiano, una cartera (Ministerio para Lauenburg); pero Guillermo evitó consumar las consecuencias politicas que acarreaba la adquisición internacional de un territorio (i.e., la incorporación al Estado). Por el contrario, el monarca Hohenzollern mantuvo durante una década la condición de Unión personal para Lauenburg (cuyos súbditos, por ejemplo, poseían nacionalidad propia), ello no obstante la oposición del Landtag prusiano a dicho status y a pesar también de que Lauenburg no fue reconocido como parte (Estado miembro) ni de la Confederación Germánica del Norte ni del posterior Imperio Alemán. Este negado reconocimiento de su subjetividad internacional no fue óbice para que el ducado conservase resortes básicos de su autodeterminación. Así, la ley prusiana del 23 de junio de 1876 disponiendo la incorporación del ducado al reino de Prusia se correspondió con una ley de Lauenburg del mismo día, aceptándola; ésta última fue sancionada por unanimidad en la Asamblea estamental del ducado. El texto de ambas normas había sido antes consensuado por las dos instancias legislativas, la de Prusia y la de Lauenburg. ${ }^{110}$

\subsection{El Estado independiente del Congo y Bélgica}

Tanto Kunz como García-Pelayo mencionan este caso al referirse a las Uniones personales. ${ }^{111}$ Aquí nos las habemos con una Unión personal en sentido estricto, si por tal entendemos las que tiene lugar entre unidades politicas (reinos o análogos) y no sólo entre el soberano de un reino y un señorío de rango menor -como en el caso anterior-. Se trata, tomado en su núcleo político, de un ejemplo de fértiles virtualidades doctrinales, por cuanto manifiesta una situación que, por un lado, no desdice las notas típicas más básicas de la Unión personal; por otro, da cuenta de uno de los modos no sólo posibles sino históricamente verificados en que ha tenido lugar una comunidad de monarca entre pueblos de asimétrica condición civilizatoria. Planteados su interés y significación, daremos sintética noticia de este breve suceso histórico.

Los antecedentes inmediatos de la entrada belga en el Congo remontan a 1876, cuando a instancias del explorador Stanley y bajo la dirección del emprendedor rey Leopoldo II de Bélgica se constituyó un Comité des Études du Haut Congo, que más tarde fue una Association Internationale du Congo, la cual comenzó la ocupación del territorio. La toma de posesión del país contó con la oposición de Inglaterra y Portugal; pero enseguida, con la iniciativa del Reich y por obra de la Conferencia Internacional del Congo -celebrada en Berlín en 1884/1885 y abocada al reparto colonial del continente africano en general-, el status político-jurídico del control del territorio por Leopoldo fue regularizado y reconocido internacionalmente. En 1885 el rey de Bélgica tomó el título de soberano del État indépendant du Congo, el cual se declaró neutral ante los otros Estados de la comunidad internacional. Vinculado por una Unión personal con Bélgica, el Congo, por decisión de su soberano, debería convertirse en colonia

110 Para los pormenores de esta Unión cfr. Wagner Norbert Berthold, "Der lauenburgische Weg nach Preussen”, http://www.humanitaeres-voelkerrecht.de/Lbg.pdf (consultado el 24/10/2019), con amplia bibliografia sobre el caso.

111 Cfr. Kunz Josef, Die Staatenverbindungen, op. cit., p. 250; García Pelayo Manuel, Derecho constitucional comparado, op. cit., p. 206. 
belga a su muerte. En el intertanto y hasta que esa subordinación colonial fue consumada se produjeron presiones internas -para acelerar el proceso de sujeción a la metrópolis-; y externas, motivadas tanto por infracciones a acuerdos internacionales y la libertad comercial, como por las extendidas acusaciones de masivos y graves atropellos a la población autóctona, explotada en la producción de caucho y marfil. En 1907 el régimen politico y administrativo del Congo conoció reformas decretadas por el rey; y al año siguiente, por donación real, Leopoldo concedió finalmente su reino a Bélgica, cuyo parlamento pasó a administrarlo a partir del 15 de noviembre de $1908 .{ }^{112}$

\subsection{El caso del Imperio Británico y la Commonwealth bajo el Estatuto de Westminster}

En los casos anteriores nos hemos encontrado con situaciones politicojurídicas distintas. Como se ha dicho en 4.3., el Estado del Congo y Bélgica eran reinos, en Unión personal bajo el mismo soberano, lo cual distinguía a esta unión de las dos restantes. Pero esa diferencia no es la única que puede detectarse. Pues, por otro lado, el Ducado de Lauenburg se hallaba vinculado a Prusia -fundamentalmente- por la persona del rey Hohenzollern, quien era también Duque de Lauenburg, y esta relación, al igual que la existente entre Leopoldo, el Congo y Bélgica, era politica. Por el contrario, el Ducado de Lancaster pasó a pertenecer al patrimonio de los reyes de Inglaterra, aunque ya no como una unidad en sí misma política (como Lauenburg o el Congo), sino como un bien usufructuado por el rey de Inglaterra. No hay una corona ducal: el Ducado pasa a ser algo de la corona, pero no algo politico; y la relación que lo une con el rey tampoco es politica. Por último, Lauenburg y Lancaster preexistían, como señorios, a Prusia y a Inglaterra, mientras que el Estado del Congo, como tal Estado, es creado por el rey de Bélgica. Vemos cómo estas tres situaciones ostentan un carácter poliédrico; y no sólo cada una de ellas inviste un perfil propio, sino que las tres son pasibles de más de una subdivisión (status de reino, o no; relación política, o de dominio; preexistencia del señorío que se une al reino principal, o no).

Comparece en cuarto lugar otro caso histórico que se aleja tanto como el de Lancaster del tipo de la Unión personal, y esto a pesar de tratarse de una relación de imperio politico. Se trata del de la Commonwealth y la corona británica. Nos referimos a la configuración que tomó el Imperio británico a mediados del s. XX, especialmente en relación con sus Dominions, es decir, con las "colonias de población" (Blackstone), territorios desiertos o cuasi desiertos en los que se había asentado población anglosajona que trasplantó su lengua, cultura, instituciones y usos politicos. Se han distinguido estos Dominions, por un lado, del Imperio colonial propiamente dicho, fruto de la conquista y el subyugamiento de poblaciones autóctonas, por otro. Son, pues, aquellas comunidades de estirpe británica, portadoras del common law y de la tradición del parlamentarismo representativo, las que a través de un proceso de paulatina autonomía

112 Cfr. Köbner Otto, Einführung in die Kolonialpolitik, Gustav Fischer, Jena, 1908, pp. 41-42, 96 y 206; Darmstaedter Paul, Geschichte der Aufteilung und Kolonisation seit dem Zeitalter der Entdeckungen, Berlin y Leipzig, 1920, 2. Band, pp. 31-45, en las que el autor, prodigando loas ditirámbicas al rey Leopoldo, historia con detalle la empresa que culminó en la constitución del Estado del Congo. 
institucional primero y relativa independencia después, darán lugar, en el período del denominado del Tercer Imperio (a partir de 1926-1931), ${ }^{113}$ a una estructura politica e internacional sui generis, anclada en la comunidad del mismo monarca: el soberano del Reino Unido.

Antes de pasar a una somera descripción del entramado constitucional del IIIer. Imperio tal como aparecerá delineado en el período de entreguerras, reportemos brevemente que la cuestión de las Uniones de Estados, en concreto de las Uniones monárquicas y en particular el de la Unión personal, estuvo presente en los encendidos debates del s. XVIII entre los colonos norteamericanos y la metrópoli británica. Entonces la distinción entre dominions of the King (i.e., la corona entendida como la persona pública del soberano) y dominions of the Crown (i.e., la corona entendida corporativamente, como el reino) ${ }^{114}$ desempeñó un papel significativo en las argumentaciones constitucionales $\mathrm{y}$, como no podia ser de otra manera, tal distinción poseyó una relevancia clave a la hora de dirimir la estructura del Imperio y los correspondientes derechos y status politicoconstitucional de las Plantations de Norteamérica. Antes de la ruptura definitiva, algunos de los protagonistas norteamericanos de la crisis subsiguiente a la Stamp Act preconizaron a la Unión personal con Gran Bretaña como la forma que mejor correspondía a los usos sancionados por el siglo y medio de vida política de las Trece Colonias. Bajo esa forma aspiraban a consolidar y reafirmar su pretensión de hallarse en un pie de igualdad frente a la nación británica y a su Parlamento soberano. Benjamin Franklin sintetiza bien dicha posición: "America is not part of the dominions of England, but of the King's dominions. England is a dominion itself, and has no dominions". ${ }^{115}$

113 Adoptamos la nomenclatura de García Pelayo Manuel (El Imperio británico, Revista de Occidente, Madrid, 1945). Las fechas de marras corresponden, respectivamente, al año en que la Conferencia Imperial nombra un Comité de relaciones interimperiales (1926), que comienza a trabajar en lo que será, finalmente, el Estatuto de Westminster, promulgado por el Parlamento británico el 11 de diciembre de 1931.

114 Ya en tiempos de los Estuardo, en "Craw vs. Ramsay", fallado bajo Carlos II respecto un contencioso casi idéntico al del axial caso "Calvin", los votos de los jueces habian entendido que los dominions of the Crown, como Irlanda, se hallaban supeditados al reino de Inglaterra y por ende a su parlamento; mientras que no ocurria lo mismo en los dominions of the King, como Escocia. Debe agregarse que no era inequivoca la significación del término "Crown" en esa época. En la baja edad media ya se había podido distinguir entre el rey como rey (es decir, su persona pública como soberano) y la corona; así fue, por ejemplo, como se adscribió al rey la función de curator coronae (cfr. Kantorowicz Ernst, Los dos cuerpos del rey, op. cit., pp. 350 y ss.); se trata precisamente de una obra clásica centrada en la historia politica inglesa). Además de otros sentidos de naturaleza corporativa o comunitaria (la corona como el reino), "corona" también ha significado el conjunto de derechos patrimoniales, señoriales y jurisdiccionales, distinto pero no separado de la persona del rey. Tales derechos, en buena parte de carácter feudovasallático, transpersonalizaban a la corona como sujeto, erigiéndolo en una entidad objetiva e impersonal (cfr. García-Pelayo Manuel, "La Corona. Estudio sobre un simbolo y un concepto politico", en Del mito y de la razón en el pensamiento político, Revista de Occidente, Madrid, 1968, p. 34).

115 Franklin Benjamin, "Observations on passages in 'An Inquire into the nature and causes of the disputes between the british colonies in America and their mother country", cap. ccclxxiii (1769), en The Works of Benjamin Franklin, including the Private as well as the Official and Scientific Correspondence, together with the Unmutilated and Correct Version of the Autobiography, compiled and edited by John Bigelow, Nueva York, Putnam, 1904 -tomado de http://oll.libertyfund.org/titles/2549 [consultado el 29/8/21017]. Para todo este tema históricoconstitucional remitimos a Castaño Sergio R. - Juri Yamila E., "Mutación constitucional y secesión política", en Revista de Historia Argentina y Americana, vol. 54, n 1, pp. 13-54. 
Casi doscientos años después de la Stamp Act (1765) -que abrió el proceso de la independencia norteamericana, con la cual se cierra el período del Primer Imperio- el Estatuto de Westminster inaugura la Mancomunidad Británica de Naciones, en la que la corona desempeña un papel fundamental. En efecto, ella es la que ha hecho que, jurídica y politicamente, los miembros de la Commonwealth no se disolvieran en el orden internacional como una pluralidad de Estados soberanos, señala García-Pelayo. ${ }^{116}$ Pues el vínculo que unía al Reino Unido y a los Dominions desde el punto de vista constitucional era la lealtad (allegiance) común a la corona. Despojada de visos feudales -y despersonalizada-, esa comunidad de lealtad ha venido a significar que ésta deba manifestarse en las mismas normas constitucionales y procedimientos politicos en todos los Estados de la Commonwealth. El monarca es rey de Gran Bretaña y de cada uno de los Dominions; y ello comporta, por ejemplo, que una reforma en la ley de sucesión al trono exija el asentimiento de todos los parlamentos: el del Reino Unido, y también el de cada uno de los Dominions. De hecho, éstos debieron prestar consentimiento a la abdicación de Eduardo VIII y luego fueron incluidos en el juramento de su sucesor, Jorge VI. La corona, como factor integrador, ha poseído la necesaria flexibilidad como para ejercer una acción independiente y separada en cada miembro de la Commonwealth. Múltiple, porque ha actuado en cada Estado aconsejada por su gobierno respectivo; una, porque los actos de la Commonwealth han adquirido tal significación sólo por referencia a esa corona.

Ahora bien, es el mismo gran teórico del Estado que nos sirve aquí de guía quien observa que no se ha tratado de varias coronas, coincidentes en el mismo titular y sujetas a la regulación constitucional-dinástica particular de cada reino, "sino de una misma corona que se despliega en varias para el ejercicio de su actividad". Y subraya: eso es "lo que diferencia radicalmente a la Commonwealth de la Unión Personal". ${ }^{117}$ Se trataría, entonces, de una sola y única corona ejerciendo señorío sobre todos los reinos/Estados, los cuales no pertenecen unos a otro (verbi gratia: los Dominions no pertenecen al Reino Unido). No es una Unión personal, ni en sentido estricto -entre reinos-, ni en sentido lato -entre un reino y un señorío menor: como Lauenburg-. Pero tampoco se asimila a la situación de Lancaster, por cuanto aquí nos las habemos con una relación de imperio político, que involucra a un rey y a varios Estados. Así pues, y salvando el peculiar modo en que pueda darse subordinación respecto de la corona británica -modo signado exclusivamente por el simbolismo integrador (Smend) y la auctoritas, mas no por el ejercicio de una potestas efectiva, como explica magistralmente GarciaPelayo-, 118 cabría afirmar que Gran Bretaña y los Dominions han sido de una corona. Rectius: la corona del Reino Unido ha sido la corona de cada uno de los Dominions, por el hecho de ser la corona del Reino Unido.

A propósito de la estructura de la Commonwealth, y aunque sin espacio ya para detenernos en la cuestión -que constituye el núcleo de una investigación más amplia, de la que el presente trabajo forma parte- no podemos con todo dejar de mencionar la tesis de Juan de Solórzano sobre el status constitucional de las Indias dentro de la monarquía hispánica. Glosando e interpretando una

116 García-Pelayo Manuel, El imperio británico, op. cit., p. 129.

117 García-Pelayo Manuel, El imperio británico, op. cit., pp. 128-132, aquí 131-132.

118 Y lo desarrollará nuevamente en el Manual de Derecho Constitucional Comparado, op. cit., al tratar del derecho constitucional británico (pp. 290-301). 
Ordenanza de 1636, Solórzano hace suya la doctrina dominante ("vulgar") según la cual los reinos, señoríos, o territorios unidos accesorie a otros "más antiguos" deben acompasar y adecuar su legislación de acuerdo con la de éstos. Ahora bien, tal principio lo aplica a la situación politica de los reinos indianos, tomando como premisa fundamental la mencionada proposición del Concilio Limeño de 1571: "[p]orque siendo de una corona los reinos de Castilla y de las Indias" [...]. ${ }^{119}$ Solórzano también da por sentado, como se ve, que las Indias se habian unido accesorie a Castilla. Pero sea como fuere de esto último, no carece de interés señalar que a juicio del jurista los distintos reinos indianos se hallaban bajo la única corona de Castilla -al igual que los distintos Dominions se han hallado bajo la única corona de Gran Bretaña e Irlanda.

\section{SÍNTESIS CONCLUSIVA}

El objetivo de este estudio ha sido presentar en escorzo un cuadro completo de las uniones de reinos (canónicamente: "Uniones personales y Uniones reales") dentro de los limitados márgenes que hoy admite un artículo científico. El señalamiento de la elaboración de tal visión sinóptica amerita ser destacado en este lugar.

Ahora bien, dentro de la masa de información histórica y análisis doctrinal que antecede, juzgamos pertinente resaltar algunas (pocas) afirmaciones $o$ conclusiones específicas.

No hay estrictamente un género común (típico) que abarque, como Uniones de reinos, a la Unión personal y a la Unión real. La Unión personal sólo es una unión de reinos per accidens.

Las Uniones personales, sujetas a distintas formas de definición en su concreción histórica, resultan el modo propio de existencia de las monarquias múltiples del orden político tradicional.

La Uniones reales, en la realidad efectiva, han sido sobre todo el resultado de procesos de descentralización política, más que de libérrimas decisiones de reinos soberanos. Como uniones de reinos han sido sobre todo, pues, uniones secundum quid.

Las Uniones personales han conocido un variado espectro de realizaciones históricas, algunas de las cuales sólo admitirian llamarse Uniones personales en sentido lato -o incluso impropio-.

Esta última proposición pone en la pista de un dato fundamental para nuestro tema: el abanico de concreciones históricas de las Uniones de reinos resulta amplísimo; y los contornos peculiares de cada una de esas concreciones se deja ajustar con dificultad a un esquema conceptual-tipológico rígido y tajante.

Enviado el / Submission date: 20/12/2019

Aceptado el / Acceptance date: 15/02/2020

119 Cfr. Politica Indiana, op. cit., L. V, cap. 16, nn. 11 y 12. Sobre el status constitucional de las Indias, cfr. las visiones contrapuestas de dos maestros de la Historia del Derecho Indiano: Zorraquín Becú Ricardo, "La condición política de las Indias", Revista de Historia del Derecho, 2 (1974) pp. 285-380 y Bravo Lira Bernardino, "El Estado en Iberoamérica", Revista Chilena de Historia del Derecho, 24 (2013-2014), pp. 191-335. 